
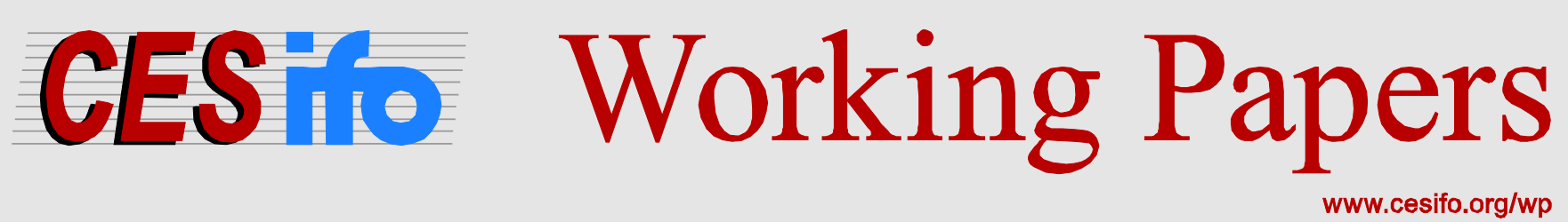

\title{
Wage Posting as a Positive Selection Device: Theory and Empirical Evidence
}

\author{
Hermann Gartner \\ Christian Holzner
}

CESIFO WORKING PAPER NO. 5494

CATEGORY 4: LABOUR MARKETS

August 2015

An electronic version of the paper may be downloaded

- from the SSRN website:

- from the RePEc website:

- from the CESifo website:

WwW.SSRN.com

Www.RePEc.org

www.CESifo-group.org/wp 


\title{
Wage Posting as a Positive Selection Device: Theory and Empirical Evidence
}

\begin{abstract}
We use the German Job Vacancy Survey to investigate whether firms are able to attract more suitable applicants by offering bargain wages rather than posting fixed wages. Contrary to the theoretical predictions provided by the literature, we find that the offer to bargain over pay decreases the share of suitable applicants. To explain these findings we develop a directed search model with asymmetric information about workers' types and incomplete contracts, which allows firms to condition their hiring decision on the match quality revealed at the job interview. We show that wage-posting and wage-bargaining firms coexist if pooling workers with different expected match quality is too costly for wage-posting firms and if the bargaining power is not too far away from satisfying the Hosios condition. In such an equilibrium wageposting firms hire only workers with a high match quality and wage-bargaining firms hire workers with a high and a medium match quality.
\end{abstract}

JEL-Code: J630, J640, M510.

Keywords: asymmetric information, match specific output, wage-posting, wage-bargaining.

Hermann Gartner Institute for Employment Research

Nuremberg / Germany hermann.gartner@iab.de

\author{
Christian Holzner \\ Ifo Institute - Leibniz Institute for \\ Economic Research \\ at the University of Munich / Germany \\ holzner@ifo.de
}

\section{August 2015}

The authors would like to thank Anja Bauer, Andrey Launov, Christian Merkl and participants of the workshops and conferences in Munich and Aix-en-Provence for useful comments and suggestions. The survey data used are confidential but not exclusive. Access to the data is provided by the Research Data Centre of the German Federal Employment Agency. For details, see: http://fdz.iab.de/en/FDZ Establishment Data/IAB Job Vacancy Survey.aspx. 


\section{Introduction}

Given the prominence of information and search frictions in the labor market firms developed different wage and recruitment policies to attract and keep high ability workers and deter low ability workers. The literature mostly proposed the use of incentive contracts to induce such self-selection of workers. ${ }^{1}$ A growing empirical literature shows that such incentive schemes can indeed induce self-selection. ${ }^{2}$ Still, the majority of jobs pay fixed wages, because in reality it is often difficult to write complete, state-contingent contracts. We know that they use job interviews to screen workers, but we know very little about the instruments they use to attract suitable workers in the first place.

Looking at job adds one sees that firms specify certain qualification requirements for the job and indicate whether or not they are willing to bargain over pay. Based on empirical evidence that performance related payment schemes are able to attract more productive applicants, vacancies that offer to bargain over pay are often thought to attract a better pool of applicants compared to vacancies that post a fixed wage. The directed search model with asymmetric information and incomplete contracts by Michelacci and Suarez (2006) delivers the respective prediction. However, wage-bargaining does not necessarily imply that wages are performance related. It can equally well be that workers and firms bargain over a fixed wage. Empirical evidence in how far wage-bargaining helps to attract a better pool of applicants is still missing.

We are the first to test whether vacancies are able to attract more suitable applicants by offering to bargain over pay rather than posting fixed wages. We use the German Job Vacancy Survey, a representative establishment dataset collected by the Institute for Employment Research (IAB), which contains numerous questions regarding the recruitment process, to investigate to which extent firms are able to attract more suitable applicants by posting wages compared to bargain on wages. We find that wage-bargaining decreases the share of suitable applicants by 5.1 percentage points or 10 percent. If we differentiate the sample by

\footnotetext{
${ }^{1}$ In the early theoretical literature Salop and Salop (1976) show that steep wage tenure profiles are used to deter applications from workers with high quitting probabilities. In Guasch and Weiss (1982) and Nalebuff and Scharfstein (1987) interviews, application fees, and contingency wages are used to deter applications from workers with low expected productivity. Wang and Weiss (1998) propose to use probation periods. Guerrieri, Shimer, and Wright (2010) and Carrillo-Tudela and Kaas (2013) have embedded this type of asymmetric information models into environments with search frictions.

${ }^{2}$ Direct evidence by Lazear (2000), who used a field experiment in a firm that changed its remuneration scheme, and Dohmen and Falk (2011), who use a lab experiment, shows that linking remuneration to individual productivity helps firms to attract more productive workers. Michaels, Handfield-Jones, and Axelrod (2001) also find that differentiating pay by productivity and offering a fast career progression based on results are effective ways to attract individual high performers. Oyer and Schaefer (2005) show that the risk-premia generated by option grants (payment in form of stock options) made by US firms are consistent with the sorting explanation.
} 
job qualification requirements, we find that the effect is driven by jobs requiring intermediate and higher qualification. The effect for jobs with no qualification requirement is insignificant and close to zero. This is plausible, as we can expect that in this sub-market most applicants are suitable.

This empirical finding is contrary to the theoretical prediction by Michelacci and Suarez (2006), who hypothesize that wage-bargaining attracts a better pool of applicants than wageposting. We modify in the second part of the paper the directed search model with asymmetric information and incomplete contracts suggested by Michelacci and Suarez (2006) to reconcile the theory with the empirical evidence. The first difference is that firms in our framework can commit to reject workers with a match quality below a certain threshold, which is essential to induce self-selection. The second important difference is that we break the perfect correlation between worker types and match quality. The perfect correlation in Michelacci and Suarez (2006) implies that wage-bargaining is equivalent to output-related pay. In our model, wagebargaining firms pay fixed wages conditional on the revealed match quality that is only imperfectly correlated with the type of a worker. With the focus on bargaining over a fixed wage compared to posting a fixed wage our model is complementary to Michelacci and Suarez (2006), who essentially model how performance-related pay versus fixed pay influences the pool of suitable applicants. Understanding this difference it becomes clear that the empirical evidence by Lazear (2000) and Dohmen and Falk (2011), who show that performance related pay attracts more productive workers, is complementary to our empirical result and supports the theory by Michelacci and Suarez (2006). Similar to Michelacci and Suarez (2006) we need the assumption that contracts are incomplete, i.e., that match quality is not verifiable, in order to ensure that wage-posting does not always dominate wage-bargaining.

\section{$1.1 \quad$ Intuition of our Model}

In our model, it is always optimal for wage-bargaining firms to accept low- and high-type workers with different expected match quality, because they can adjust the wage according to a surplus sharing rule to the match quality that is revealed. Wage-posting firms commit to paying a unique wage to all workers that pass the posted hiring threshold for match quality. They have to choose between a separating and a pooling strategy. Separating means, they set the match quality hiring threshold such that only workers with a high expected match quality apply. Pooling means, they attract also workers with a low expected match quality. The cost of using the pooling strategy is the higher the higher the expected match quality difference between low- and high-type workers and the higher the share of low-type worker, 
who have a low expected match quality.

The type of equilibrium that prevails in our model crucially depends on the cost of the pooling strategy and on how close worker's bargaining power is to satisfying the Hosios (1990) condition. If the cost of pooling workers is high, all firms post wages and choose a separation strategy, where they hire only workers with a high match quality. In this separating case wage-posting is optimal since wage-posting ensures efficiency for a homogenous group of workers as shown by Peters (1991); Moen (1997); Acemoglu and Shimer (1999) and Burdett, Shi, and Wright (2001) among others.

If the cost of pooling workers with different expected match qualities is in the medium range the bargaining parameter plays a crucial role in determining the type of equilibrium that exists. If a worker's bargaining power is close to satisfying the Hosios condition, wagebargaining dominates wage-posting because wage-bargaining allows firms to offer different wages to workers with different match quality. As bargaining power is further away from satisfying the Hosios condition, wage-bargaining becomes less attractive due to the search inefficiency associated with wage-bargaining. This triggers entry of wage-posting firms, and wage-posting and wage-bargaining coexist. Wage-posting firms will hire only workers with a high match quality and wage-bargaining firms will hire workers with a high and a medium match quality. Workers with a low match quality are rejected by both firms. This does not necessarily imply that wage-posting firms attract more suitable applicants. To see this note that according to our theory, wage-posting firms will classify applicants with a high match quality as suitable while wage-bargaining firms classify applicants with a high and medium match quality as suitable. Thus, only if the probability that a high-type worker draws a high match quality is sufficiently high, then our theory predicts the observed empirical correlation that wage-bargaining firms attract a higher fraction of suitable workers.

If the cost of pooling workers with different expected match quality is low, wage-posting firms will also start to hire workers with a medium match quality. At extreme values for workers' bargaining power wage-posting dominates. If workers' bargaining power is close to satisfying the Hosios condition, wage-bargaining dominates. For intermediate values adverse selection leads to market failure, because wage-posting firms, which offer a common wage for workers, attract all low-type workers. This makes a deviation to wage-bargaining, where only high-type workers apply profitable. Hence a coexistence equilibrium with wage-posting and wage-bargaining does not exist. A pure wage-bargaining equilibrium cannot exist either, since workers' bargaining power is too far away from satisfying the Hosios condition, which implies that a deviation to wage-posting is profitable. 


\subsection{Implications for the Bargaining Power}

In order to get some idea where the empirical bargaining power of workers lies, we also investigate whether wage-bargaining compared to wage-posting helps to attract more applicants. In all our regressions the effect of wage-bargaining is insignificant and close to zero. This result indicates two things.

First, the search inefficiency inherent in wage-bargaining is not large. This suggests that the bargaining power does not take an extreme value. This is one prerequisite for the coexistence of wage-posting and wage-bargaining.

Second, the bargaining power of workers is below the optimal level satisfying the Hosios condition. This conclusion is based on our theoretical prediction that in an equilibrium where wage-bargaining and wage-posting coexist wage-posting firms attract only high-type workers while wage-bargaining firms attract high- and low-type workers. This implies that wage-bargaining firms would attract more applicants than wage-posting firms if the Hosios condition holds. With a bargaining power of workers below the level satisfying the Hosios condition the expected utility from applying to wage-bargaining firms is however lower. This ensures that the number of applicants at wage-bargaining firms is on average the same as the number of applicants at wage-posting firms.

\subsection{Relation to the Literature}

Besides Michelacci and Suarez (2006), our model is also related to Delacroix and Shi (2013). They consider a directed search model with signaling, where sellers can distort their posted prices upward in order to signal high quality. The upward distortion of posted price can lead to inefficient entry of seller. If the inefficiency is high enough and worker's bargaining power close enough to satisfying the efficiency condition of Hosios (1990), firms find it optimal to bargain. Delacroix and Shi (2013) investigate the efficiency of wage-bargaining versus wageposting only for perfect signals. We conjecture that the use of a prefect signal is the reason why they do not find a parameter region where both regimes coexist. But even if they allowed for imprecise signals and established coexistence, their theory would not be able to explain that wage-bargaining is associated with a less suited pool of applicants. The reason is that bargaining firms always prefer to produce high quality goods, because of the assumption that the average cost of production does not increase with quality. Even if an exogenous-quality type model with an imprecise signal in the spirit of Delacroix and Shi (2013) might be able to produce similar predictions as our model, the trade-off between wage-posting and wage- 
bargaining has a different cause. To see this, note that in our model posted wages are not distorted since we allow firms to commit not only to a wage but also to a match quality hiring threshold. It is this hiring threshold that forces firms to reject workers with a medium match quality and not the upward distorted price as in Delacroix and Shi (2013) that causes the inefficiency associated with wage-posting.

Another strand of the literature uses random search models with private information to analyze the trade-off between wage-posting and wage-bargaining. Bester (1993) uses a framework where buyers observe product quality after meeting the seller, under these conditions firms prefer bargaining compared to price-posting as a commitment device to produce high quality goods. Ellingsen and Rosen (2003) show that wage-bargaining can constitute an equilibrium if an increase in the reservation wage resulting from a productivity shock has more impact on posted wages than bargained wages. Camera and Delacroix (2004) show that bargaining can be optimal if the trading delay caused by the information eliciting process of price-posting under asymmetric information is too costly.

Our theory is also related to other search models with private information. Menzio (2007) considers wage-bargaining in a framework where firms use cheap talk to signal private information about the quality of a vacancy. Guerrieri, Shimer, and Wright (2010) consider the case of complete contracts and establish that only a separating equilibrium exists. Carrillo-Tudela and Kaas (2013) investigate in a random on-the-job search framework with asymmetric information how different promotion contracts can be used to sort worker types. There is also a large body of literature devoted to competing auctions, ${ }^{3}$ where sellers use auctions to direct buyers with private information.

\subsection{Outline of the Article}

The paper is organized as follows. In section 2 we describe the dataset and present the empirical analysis. In section 3 we present our theoretical model in order to explain the empirical findings. Section 4 concludes. The Appendix contains proofs, descriptive statistics and additional regression results.

\section{Empirical Analysis}

The main focus of our empirical analysis is on the correlation between wage-bargaining and the fraction of suitable applicants. Michelacci and Suarez (2006) show that wage-posting

\footnotetext{
${ }^{3}$ See McAfee (1993); Peters and Severinov (1997); Albrecht, Gautier, and Vroman (2012) and Albrecht, Gautier, and Vroman (2014) among others.
} 
and wage-bargaining coexist, if the bargaining power is not too far away from satisfying the Hosios condition. We first test whether the bargaining power is close to satisfying the Hosios condition by analyzing whether wage-bargaining firms attract a similar number of applicants as wage-posting firms. Once we have established that there is no significant difference in the number of applicants between the two recruitment policies, we investigate the correlation between wage-bargaining and the fraction of suitable applicants. We start, however, with a description of our dataset, the German Job Vacancy Survey, and a discussion about identification.

\subsection{German Job Vacancy Survey}

For our empirical analysis we use the German Job Vacancy Survey, a dataset collected by the Institute for Employment Research (IAB) based on a representative sample of establishments. The yearly survey started in 1989 and was initially conducted to provide an estimate of the total number of vacancies in Germany relative to the number of vacancies registered with the public employment agency. The German Job Vacancy Survey provides a repeated cross section, not a panel dataset.

The survey provides information about plant size, workforce composition, and the industry of the establishment. The economic conditions of an establishment can be proxied by binary indicator variables for "low sales" and "skilled labor shortage". It also contains a number of questions concerning the last case of a successfully filled vacancy. We have information on the recruitment process, such as the number of applicants, the number of suitable applicants, and the search channels used by the establishments. Also, various job characteristics are available; qualification and experience level required for the job, part-time/full-time, and temporary/permanent. Since 2011, the survey also includes the question: "Did you negotiate with the applicant about remuneration (basic salary and further components if applicable)?" Respondents had three choices to answers: "Yes", "No, fixed offer made by the establishment", or "No, for other reasons ...". 4

We use data for the years 2011 through 2013. Overall, 42,965 establishments have taken part in the survey in the years 2011 to $2013,28,648$ searched at least once in the last 12 month for a worker. Because of multiple searches per establishment there are about 430,000 searches

\footnotetext{
${ }^{4}$ Note that the last item "No, for other reasons" (chosen in 1,211 cases) offers an open answer. We thoroughly analyzed these open answers. Most of them meant essentially the same thing as a fixed offer (for instance, by referring to a collectively agreed wage or piece rate). We recoded them to "No, fixed offer made by the establishment". The remaining 29 cases answer "the first offer was accepted". In these cases our interpretation is that the employer would bargain when the first offer were rejected. This cases are defined as bargaining.
} 
in total. About 20,000 (or 4.6 percent) searches ended without recruiting a worker. 28,144 establishments answered the question on the most recent case of a successfully filled vacancy. Since we are interested in the recruitment process of firms in a decentralized search market and its implication for the workers application and selection behavior, we exclude vacancies, where the hiring firm exclusively used a recruitment channel without search frictions, such as the internal job market, recommendations by employees, and the selection from former apprentices or interns. We thus drop 4,773 cases. Further observations had to be dropped because of item non-response. The respective number of observations is reported in the respective tables.

\subsection{Identification}

We do not have a natural experiment that would give us truly exogenous variation in wagebargaining compared to wage-posting. Our dataset, however, provides more information than most other datasets to control not only for firm-level but also for vacancy-level characteristics. Most importantly, we have information on the skill and experience level required for the vacant job and can control for job characteristics like part-time/full-time, and permanent/temporary. We can also control for firm size, as well as the economic condition of the firm as captured by the binary indicator variables "low sales" and "skilled labor shortage", and the regional unemployment rate. It could still be the case that there are unobservable characteristics which influence a firms' decision to bargain over the wage and which are correlated with the share of suitable applicants. If the unobserved characteristic varies on the industrial level, then this is controlled for by including industry-fixed-effects.

We also want to rule out that vacancies, which were unsuccessful in receiving enough suitable applicants initially, switch from wage-posting to wage-bargaining (or vice versa) during the recruitment process in order to increase their chances to attract suitable candidates. To test this reverse causality hypothesis we use information on the earliest intended starting date for the employment relationship and the date at which the firm decided to hire the applicant. This enables us to exclude all vacancies where the firm decided to hire the applicant after the intended employment starting date. The respective subsample should, therefore, no longer include firms which were unsuccessful in their first recruitment attempt and decided in a second attempt to change their recruitment policy. The fact that our results do not change irrespective of whether we take the whole or the reduced sample indicates that firms do not change their recruitment policy over time. We therefore do not worry too much about reverse causality. This is in line with the evidence by Brencic and Norris (2010), who show that 
employers do not change their job ads posted on www.monster.com over time, and earlier evidence by van Ours and Ridder (1992) and Abbring and van Ours (1994), who find that employers search non-sequential, i.e., collect many applicants in the first weeks after opening the vacancy and spend most time on selecting the right worker.

\subsection{Wage-posting vs. Wage-bargaining Firms}

We start with a descriptive analysis comparing vacancies for which firms decided to post or bargain for wages. Empirical evidence by Hall and Krueger (2012) for the US and Brenzel, Gartner, and Schnabel (2014) for Germany suggests that wage-bargaining was used in 37 or 38 percent of all hirings and wage-posting in 63 to 62 percent.

Table 1: Descriptive statistics comparing wage-bargaining with wage-posting

\begin{tabular}{|c|c|c|c|}
\hline & (1) & $(2)$ & (3) \\
\hline & All & Wage-bargaining & Wage-posting \\
\hline \multicolumn{4}{|l|}{ Establishment characteristics } \\
\hline Bargaining & 0.331 & & \\
\hline Applicants & 15.730 & 14.63 & 16.28 \\
\hline Share of suitable applicants* & 0.478 & 0.443 & 0.495 \\
\hline Employees & 176.85 & 140.35 & 194.94 \\
\hline Share of female employees & 0.467 & 0.410 & 0.495 \\
\hline Share of temporary employees & 0.106 & 0.085 & 0.116 \\
\hline Share of part-time employees & 0.232 & 0.167 & 0.264 \\
\hline \multicolumn{2}{|l|}{ Characteristics of the vacancy } & \multicolumn{2}{|c|}{ percent of column (1) } \\
\hline Part time job & 0.123 & 0.173 & 0.827 \\
\hline Unqualified & 0.095 & 0.191 & 0.809 \\
\hline Intermediate qualification & 0.697 & 0.328 & 0.672 \\
\hline Higher qualification & 0.208 & 0.408 & 0.592 \\
\hline Observations & 15,166 & 5,026 & 10,140 \\
\hline
\end{tabular}

Source: German Job Vacancy Survey 2011-2013.

*) based on 14,519 observations as zeros-cases are excluded.

In our sample, firms chose to negotiate the wage with their applicants in 33 percent of all filled vacancies. As shown in Table 1 wage-bargaining firms are on average smaller, attract less applicants, have a lower fraction of suitable applicants, employ less women and have a lower fraction of temporary or part-time jobs. Firms and workers are more likely to offer to negotiate the wage for vacancies in permanent and full-time jobs. Hardly surprising, the 
tendency to negotiate the wage also increases with the qualification requirement of the job.

Further insight into which characteristics of firms, jobs and workers that are influence in a firm's decision to post or bargain wages can be found in Brenzel et al. (2014), who use the same dataset for 2011.

\section{$2.4 \quad$ Number of Applicants}

Successfully filled vacancies of firms that post wages attracted on average 14.6 applicants. Vacancies of firms that bargain over wages attracted on average 16.3 applicants. This small difference is not surprising given that the distributions (pdf) of the number of applicants are almost identical for both groups of vacancies as Figure 1a shows. Figure 1b illustrates that the cumulative distributions of wage-posting and wage-bargaining are almost the same.

Figure 1: Distribution of total number of applicants
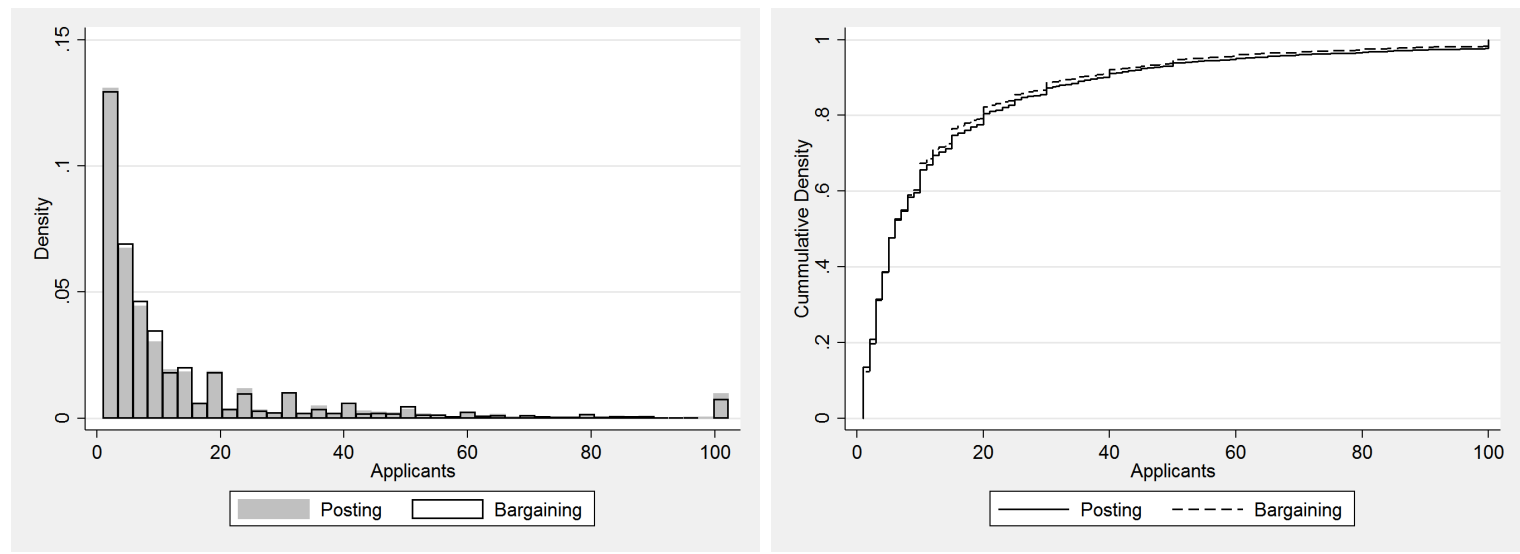

Source: German Job Vacancy Survey 2011-2013. 100 includes 100 or more.

In Table 2 we control for observable firm- and job-characteristics by including establishment size dummies, the share of highly qualified, female, part-time and temporary employees, binary indicator variables for the economic condition of the establishment like "low sales" and "skilled labor shortage", dummies for the qualification and experience requirements of the job, an indicator variable for a newly created job, and a part-time job. ${ }^{5}$ In addition we include year- and industry-fixed-effects. As a regional time-varying control we also include the regional unemployment rate. Table 2 provides the estimated coefficient for the binary indicator variable, which equals 1 if firms offered to bargain over the wage and zero if they offered a fixed wage. The remaining regression coefficients can be found in Table B.2 in the

\footnotetext{
${ }^{5}$ We have also estimated models including a dummy for temporary jobs. As the effect is insignificant and since we lost many observations because of missing observations, we present the version without the dummy for temporary jobs. The results remain the same.
} 
Appendix.

The OLS coefficient estimate for the wage-bargaining indicator variable in column 1 of Table 2 is equal to -0.012 with a standard error of 0.018 . In column 2 we present the corresponding zero-truncated negative binomial regression coefficient estimate to account for the fact that the number of applicants is a count variable with overdispersion as indicated by the significant $\alpha$-parameters displayed in Table B.2 in the Appendix. We use the zerotruncated specification, since our sample only includes vacancies which were successful in hiring a worker, i.e., had at least one applicant. We use the same control variables as in the OLS regression.

Table 2: Regression on the number of applicants

\begin{tabular}{lcccc}
\hline & 1 & 2 & 3 & 4 \\
& OLS & ZTNB & OLS & ZTNB \\
\hline Bargaining & 0.0118 & 0.0141 & -0.0118 & 0.0125 \\
& $(0.0183)$ & $(0.0380)$ & $(0.0222)$ & $(0.0444)$ \\
\hline$R^{2}$ & 0.1381 & & 0.1387 & \\
ln L & & $-53,010.2$ & & $-38,061.7$ \\
Observations & 15,166 & 15,166 & 10,907 & 10,907 \\
\hline
\end{tabular}

Source: German Job Vacancy Survey 2011-2013. ZTNB means zero-truncated negative binomial regression. Columns 3 and 4 exclude cases were the decision for the new employee was later than the planed first working day. Robust standard errors in brackets. The coefficients of the control variables can be found in Table B.2 in the Appendix. ${ }^{* * *}$ indicates $p<0.01$ * $^{*} p<0.05 ;{ }^{*} p<0.1$.

The coefficient for the wage-bargaining binary indicator variable based on OLS and on the zero-truncated negative binomial regression are statistically insignificant and close to zero. The small magnitude of this coefficient indicates that worker's bargaining power not too far away from satisfying the Hosios condition. Thus, wage-posting and wage-bargaining should, according to Michelacci and Suarez (2006) and our theory presented in section 3, coexist.

One may be worried that in cases when the recruiting was difficult, the employer may have switched from posting a fixed wage to bargaining. Bargaining would then be endogenous and our estimates biased. We therefore conduct the following robustness check presented in columns 3 and 4 of Table 2. We exclude cases, when the decision for the new worker was made after the first intended starting date of the employment relationship. Since the results in columns 3 and 4 are basically the same as in columns 1 and 2, we conclude that the results are not biased by this potential endogeneity bias. We also run separate regressions for the 
different qualification levels required for the job (shown in Table B.3 in the Appendix) for the OLS and the zero-truncated negative binomial regressions. In all cases the wage-bargaining indicator variable is insignificant and close to zero.

Wage-posting might be more attractive because posted wages are more common in unionized firms where wages are individually fixed by union agreements (see Brenzel et al. (2014) for the respective evidence). Since unionized firms might pay more generous wages as well, the results could be biased by ignoring the union status of the firm. To check this we include a indicator variable that captures the union status of the firm. The results remain unchanged as shown in Appendix B.6. We did not include the union status of the firm in our baseline regression, since we did not want to take away the respective variation in wage-posting versus wage-bargaining.

\subsection{Fraction of Suitable Applicants}

Since our sample includes only vacancies that where successfully filled, we can conclude that all vacancies in our sample received at least one application from a suitable candidate. Our analysis is therefore conditional on having at least one suitable candidate.

Figure 2: Distribution of the fraction of suitable applicants
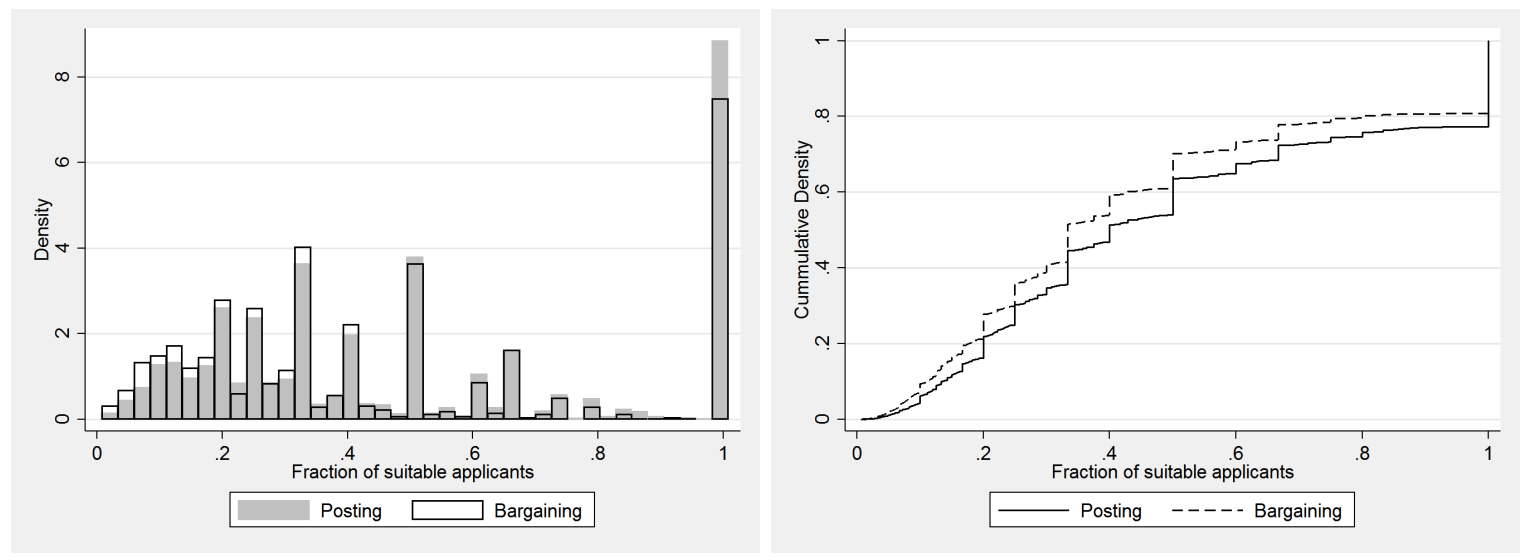

Source: German Job Vacancy Survey 2011-2013.

The share of suitable applicants is roughly 5 percentage points higher at vacancies for which firms decided to post wages (49.5 percent) than at vacancies for which firms decided to bargain over the wage (44.3 percent). Figure 2a depicts the probability density function of the share of suitable applicants for both types of recruitment policies. It shows that vacancies of firms that decided to post wages tend to have higher share of suitable applicants. This is also confirmed by Figure 2b, which shows that the cumulative density distribution for the 
share of suitable applicants of vacancies which posted fixed wages first-order stochastically dominates (is always below) the cumulative density distribution of vacancies which offer to bargain.

In Table 3 we control for the same observable characteristics as in Table 2. Table 3 provides the estimated coefficient for the binary indicator variable of wage-bargaining on the number of suitable applicants controlling for the overall number of applicants on the rhs of the regression. We can therefore interpret the coefficients as changing the share of suitable applicants by $\beta \cdot 100$ percentage points. The full regression with all coefficients can be found in Table B.4 in the Appendix. Table 3 presents the OLS regression result in column 1 and the zero-truncated negative binomial regression result in column 2. The OLS coefficient of -0.051 is highly significant and implies that the share of suitable applicants is 5.1 percentage points lower if firms offer wage-bargaining. Given that the average share of suitable applicants at wage-posting firms is 49.5 percent, 5.1 percentage points are equivalent to a reduction of 10 percent. The results obtained by the zero-truncated negative binomial regression suggest an effect of similar size, namely a reduction by 9.58 percent.

Table 3: Regression on number of suitable applicants

\begin{tabular}{lcccc}
\hline & 1 & 2 & 3 & 4 \\
& OLS & ZTNB & OLS & ZTNB \\
\hline Bargaining & $-0.0508^{* * *}$ & $-0.0958^{* * *}$ & $0.0577^{* * *}$ & $-0.1203^{* * *}$ \\
& $(0.0103)$ & $(0.0199)$ & $(0.0124)$ & $(0.0239)$ \\
\hline$R^{2}$ & 0.623 & & 0.637 & \\
ln L & & $-25,913.4$ & & $-18,998.0$ \\
Observations & 14,519 & 14,519 & 10,462 & 10,462 \\
\hline
\end{tabular}

Source: German Job Vacancy Survey 2011-2013. ZTNB means zero-truncated negative binomial regression. Columns 3 and 4 exclude cases were the decision for the new employee was later than the planed first working day. Robust standard errors in brackets. The coefficients of the control variables can be found in Table B.4 in the Appendix. ${ }^{* * *}$ indicates $p<0.01{ }^{* *} p<0.05 ;{ }^{*} p<0.1$.

As a robustness check we replicate the OLS and zero-truncated negative binomial regressions for the smaller sample where we exclude workers where the firm decided on the new worker after the first intended starting date of the employment relationship. Again, the fact that the results in columns 3 and 4 are very similar to the results in columns 1 and 2 suggests that we do not have to worry about reverse causality. The results remain also unchanged, if we include the union status of the firm as shown in Appendix B.6. 
Table 4: Number of suitable applicants by qualification

\begin{tabular}{|c|c|c|c|}
\hline & Unqualified & $\begin{array}{l}\text { Intermediate } \\
\text { qualification }\end{array}$ & $\begin{array}{c}\text { Higher } \\
\text { qualification }\end{array}$ \\
\hline \multirow[t]{2}{*}{ Bargaining } & 0.0166 & $-0.0560^{* * *}$ & $-0.0523^{* *}$ \\
\hline & $(0.0388)$ & $(0.0118)$ & $(0.0251)$ \\
\hline$R^{2}$ & 0.647 & 0.631 & 0.589 \\
\hline Observations & 1,371 & 10,118 & 3,030 \\
\hline
\end{tabular}

Source: German Job Vacancy Survey 2011-2013. Robust standard errors in brackets. The coefficients of the control variables can be found in Table B.5 in the Appendix. ${ }^{* * *}$ indicates $p<0.01 ;{ }^{* *} p<0.05 ;{ }^{*} p<0.1$.

In Table 4 we present the results of separate regressions for the different qualification levels required for the job. For jobs that require no qualification we find no significant correlation between wage-bargaining and the share of suitable applicants. This is exactly what we expected. The overall negative correlation between wage-bargaining and the share of suitable applicants is driven by jobs requiring intermediate and higher qualifications. Here, the wagebargaining coefficient equals -0.056 and is significant at the 1 percent level for intermediate qualifications, and -0.053 at a 5 percent level for higher qualifications. The results remain unchanged, if we include the union status of the firm as shown in Appendix B.6.

As a robustness check we run the regression also for a range of subgroups. We estimate the model for different classes of firm size, separately for public sector, production sector and service sector, part-time and full-time jobs, temporary and permanent jobs and jobs requiring experience or not. The results are robust for all subgroups and available upon request.

The finding of our analysis is that wage-bargaining attracts a lower fraction of suitable applicants for intermediate and higher qualification jobs. This result contradicts Michelacci and Suarez (2006). The remainder of this paper devoted to developing a theory that is consistent with the finding that wage-posting attracts on average more suitable applicants.

\section{Theoretical Part}

We modify the model by Michelacci and Suarez (2006) by allowing firms to screen their applicants before they hire a worker and to condition their hiring decision on the revealed match quality. This can induce ex-ante sorting of workers and can ensure that the number of suitable applicants is higher at firms that post wages. 


\subsection{Framework}

We consider a static model with a unit mass of risk neutral workers, who are unemployed and search for a job. The meeting technology is described below. Productivity is match specific. Workers and firms learn the quality of a match at the job interview. Match quality (output) can take a low, medium or high value $y_{i} \in\left\{0, y^{m}, 1\right\}$, with $0<y^{m}<1$. We assume that match quality is not verifiable, i.e., posted wages cannot be conditioned on it. Workers differ in the probability to with which they draw a certain match quality. High-type workers draw a high match quality $y_{i}=1$ with probability $\pi$, and a medium match quality $y_{i}=y^{m}$ with probability $1-\pi$. Low-type workers also draw a medium match quality $y_{i}=y^{m}$ with probability $1-\pi$ and a low match quality $y_{i}=0$ with probability $\pi$. The fraction of high-type unemployed workers is denoted by $m$.

The timing of events is given as follows. In the first stage, firms decide whether to open a vacancy given the cost $k$ of vacancy creation and whether post a fixed wage or offer to bargain over the wage. To ensure the existence of an equilibrium where both types of workers are active we assume $k$ sufficiently small. The resulting mass of firms posting a fixed wage is denoted by $v$ and the mass of firms offering to bargain by $v_{\varnothing}$. The wage associated with the offer to bargain is denoted by $w_{\varnothing}$. In the second stage, all firms that decide to post wages simultaneously decide on the wage offer $w$ and the hiring threshold $\bar{y}$, i.e., they commit to hire only workers with a match quality $y_{i} \geq \bar{y}$. Wage-posting firms can only offer one wage and not a quality-dependent wage menu, since the quality of a match is assumed to be not verifiable. Also wage-bargaining firms can commit to a hiring threshold, which we denote by $\bar{y}_{\varnothing}$. In the third stage, workers observe the posted wages and the wage-bargaining offers and decide where to apply. They can only apply to one firm. The fractions of high-type and low-type workers that apply to wage-posting firms are denoted by $\gamma^{h}$ and $\gamma^{l}$. In the fourth stage, firms select one applicant at random to interview (if they have at least one applicant). For simplicity we assume that it is too costly for the firm to interview a second worker. Thus, all other applicants remain unemployed. Workers and firms observe match quality $y_{i}$ at the interview. The firm decides whether or not to offer the job to this applicant. In the fifth stage, wages are negotiated at those firms that offer to bargain. Workers bargaining power is denoted by $\beta$. In the final stage, matches are formed, the posted or bargained wages are paid and production takes place. The payoff of unmatched workers and firms is normalized to 0 . We solve the model by backward induction. 


\subsection{Payoffs and Expected Profits}

Wage-bargaining (fifth stage): We will use Nash-bargaining surplus splitting rule, which implies that the bargaining wage equals $w_{\varnothing}=\beta y_{i}$. The profit of the firm is given by $(1-\beta) y_{i}$.

Firms' selection decision (fourth stage): Firms observe for the applicant they decided to interview the quality of the match. If the quality is above the hiring threshold $y_{i} \geq \bar{y}$ $\left(y_{i} \geq \bar{y}_{\varnothing}\right)$ then the wage-posting (wage-bargaining) firm will hire the worker.

Worker's application decision (third stage): Let us for the moment assume the existence of an equilibrium where high-type workers receive the expected market utility $U_{s}^{*} \geq 0$ and the low-type worker receive $U_{u}^{*} \geq 0$. We assume that workers that have no chance of being hired at a given hiring threshold $\bar{y}$ or $\bar{y}_{\varnothing}$ will not apply at the respective firm.

Consider first the worker's utility of applying at firms that offer to bargain the wage, i.e., offer $w_{\varnothing}$, and set a hiring threshold $\bar{y}_{\varnothing}$. The expected number of applicants that a wagebargaining firm with a hiring threshold $\bar{y}_{\varnothing}$ receives is given by the expected queue length,

$$
x\left(w_{\varnothing} \mid \bar{y}_{\varnothing}\right)= \begin{cases}\frac{m\left(1-\gamma^{h}\right)+(1-m)\left(1-\gamma^{l}\right)}{v_{\varnothing}} & \text { if } \bar{y}_{\varnothing}=y^{m}, \\ \frac{m\left(1-\gamma^{h}\right)}{v_{\varnothing}} & \text { if } \bar{y}_{\varnothing}=1 .\end{cases}
$$

Note that $m\left(1-\gamma^{h}\right)$ is the mass of high-type and $(1-m)\left(1-\gamma^{l}\right)$ the mass of low-type workers applying for wage-bargaining. $v_{\varnothing}$ is the mass of wage-bargaining firms. The probability that a given applicant is selected for the job interview is according to the Urnball-matching function given by,

$$
\eta\left(x\left(w_{\varnothing} \mid \bar{y}_{\varnothing}\right)\right)=\frac{1-e^{-x\left(w_{\varnothing} \mid \bar{y}_{\varnothing}\right)}}{x\left(w_{\varnothing} \mid \bar{y}_{\varnothing}\right)} .
$$

The expected utilities of a high- and low-type worker from applying at a bargaining firm with a hiring threshold $\bar{y}_{\varnothing}$ are given by,

$$
\begin{aligned}
& U_{h}\left(w_{\varnothing} \mid \bar{y}_{\varnothing}\right)= \begin{cases}\eta\left(x\left(w_{\varnothing} \mid y^{m}\right)\right)\left(\pi \beta+(1-\pi) \beta y^{m}\right) & \text { if } \bar{y}_{\varnothing}=y^{m}, \\
\eta\left(x\left(w_{\varnothing} \mid 1\right)\right) \pi \beta & \text { if } \bar{y}_{\varnothing}=1,\end{cases} \\
& U_{l}\left(w_{\varnothing} \mid \bar{y}_{\varnothing}\right)= \begin{cases}\eta\left(x\left(w_{\varnothing} \mid y^{m}\right)\right)(1-\pi) \beta y^{m} & \text { if } \bar{y}_{\varnothing}=y^{m}, \\
0 & \text { if } \bar{y}_{\varnothing}=1,\end{cases}
\end{aligned}
$$

because the probability that a high-type (low-type) worker draws a high (low) match quality $1(0)$ is given by $\pi$ and the probability that either worker draws a medium match quality $y^{m}$ is given by $1-\pi$. 
Let us now derive the expected utility of a worker, who applies at a wage-posting firm that offers a wage $w^{\prime}$ and a hiring threshold $\bar{y}^{\prime}$ while all other wage-posting firms offer the equilibrium wage $w$ and a hiring threshold $\bar{y}$. The equilibrium queue length associated with the wage $w$ and a hiring threshold $\bar{y}$ is given by,

$$
x(w \mid \bar{y})= \begin{cases}\frac{m \gamma^{h}+(1-m) \gamma^{l}}{v} & \text { if } \bar{y}=y^{m}, \\ \frac{m \gamma^{h}}{v} & \text { if } \bar{y}=1 .\end{cases}
$$

Note that $m \gamma^{h}$ is the mass of suitable workers and $(1-m) \gamma^{l}$ the mass of unsuitable worker applying for wage-posting. The mass of wage-posting firms equals $v$. The queue length associated with the deviating wage offer $w^{\prime}$ and a hiring threshold $\bar{y}^{\prime}$ is denoted by $x\left(w^{\prime} \mid \bar{y}^{\prime}\right)$. The expected utilities of a high- and low-type worker from applying at the deviating firm are given by,

$$
\begin{aligned}
& U_{h}\left(w^{\prime} \mid \bar{y}^{\prime}\right)= \begin{cases}\eta\left(x\left(w^{\prime} \mid y^{m}\right)\right) w^{\prime} & \text { if } \bar{y}=y^{m}, \\
\eta\left(x\left(w^{\prime} \mid 1\right)\right) \pi w^{\prime} & \text { if } \bar{y}=1,\end{cases} \\
& U_{l}\left(w^{\prime} \mid \bar{y}^{\prime}\right)= \begin{cases}\eta\left(x\left(w^{\prime} \mid y^{m}\right)\right)(1-\pi) w^{\prime} & \text { if } \bar{y}=y^{m}, \\
0 & \text { if } \bar{y}=1 .\end{cases}
\end{aligned}
$$

Equation (5) defines implicitly the expected queue length of workers $x^{\prime} \equiv x\left(w^{\prime} \mid U_{h}^{*}\right)$ as a strictly increasing function of $w^{\prime}$.

Given the utilities of high- and low-type workers in wage-posting and wage-bargaining firms we can characterize the application decision of workers. High-type workers will apply at wage-bargaining (wage-posting) firms, if the expected utility $U_{h}\left(w_{\varnothing} \mid \bar{y}_{\varnothing}\right)\left(U_{h}(w \mid \bar{y})\right)$ is at least as high as the utility $U_{h}^{*}$ and low-type workers will apply at wage-bargaining (wageposting) firms, if the expected utility $U_{l}\left(w_{\varnothing} \mid \bar{y}_{\varnothing}\right)\left(U_{l}(w \mid \bar{y})\right)$ is at least as high as the utility $U_{l}^{*}$. If workers are indifferent about applying to a wage-posting or a wage-bargaining firm they use a mixed application strategy. If high-type workers are indifferent between wageposting and wage-bargaining low-type workers always apply at wage-posting firms, if both types of firms offer a hiring threshold $\bar{y}=\bar{y}_{\varnothing}=y^{m}$. This is shown in the following Lemma.

Lemma 1 Assume that both types of firms hire workers with medium match quality $y^{m}$ and that high-type workers are indifferent about applying to wage-posting or wage-bargaining firms, i.e., $U_{h}\left(w_{\varnothing} \mid y^{m}\right)=U_{h}\left(w \mid y^{m}\right)$, then all low-type workers apply to wage-posting firms, i.e., $\gamma^{l}=1$.

Proof: The relative utility of low-type to high-type workers in both regimes implies,

$$
\frac{U_{l}\left(w \mid y^{m}\right)}{U_{h}\left(w \mid y^{m}\right)}=(1-\pi)>\frac{(1-\pi) y^{m}}{\pi+(1-\pi) y^{m}}=\frac{U_{l}\left(w_{\varnothing} \mid y^{m}\right)}{U_{h}\left(w_{\varnothing} \mid y^{m}\right)}
$$


since $y^{m}<1 . Q E D$

In the spirit of Michelacci and Suarez (2006) Lemma 1 shows that wage-posting is, due to the fact that it offers the same wage to both low- and high-type workers, prone for adverse selection, if both wage-bargaining and wage-posting firms offer to hire workers with match quality $y^{m}$. Lemma 1 implies that if wage-posting firms use a hiring threshold $\bar{y}=y^{m}$ all low-type workers apply to wage-posting firms. This implies in turn that low-type workers only apply to wage-bargaining firms with a hiring threshold $\bar{y}_{\varnothing}=y^{m}$ if wage-posting firms use a hiring threshold $\bar{y}=1$ or no wage-posting firms exist.

Firms' wage offers and hiring thresholds (second stage): Let us first consider the optimal wage offer of firms that set the hiring threshold $\bar{y}^{\prime}=y^{m}$ such that also matches with a medium match quality are formed. Wage-posting firms decide on the wage offer $w^{\prime}$ taking the market utility $U_{h}^{*}$ of high-type workers as given. Lemma 1 then implies that all low-type workers also apply. The wage-posting firm chooses $w^{\prime}$ to maximize profits, i.e.,

$$
w\left(U_{h}^{*}\right)=\arg \max _{w^{\prime}} x\left(w^{\prime} \mid U_{h}^{*}\right) \eta\left(x\left(w^{\prime} \mid U_{h}^{*}\right)\right)\left[\frac{m \gamma^{h} \pi\left(1-w^{\prime}\right)}{m \gamma^{h}+(1-m)}+(1-\pi)\left(y^{m}-w^{\prime}\right)\right] .
$$

The probability of a firm receiving at least one applicant by posting a wage $w^{\prime}$ is given by $x\left(w^{\prime} \mid U_{h}\right) \eta\left(x\left(w^{\prime} \mid U_{h}\right)\right)$. The firm is only able to interview one applicant. With probability $m \gamma^{h} \pi /\left(m \gamma^{h}+(1-m)\right)$ the randomly selected applicant is of high type and the match quality is equal to 1 . With probability $(1-\pi)$ the match quality is given by $y^{m}$. With probability $(1-m) \pi /\left(m \gamma^{h}+(1-m)\right)$ the randomly selected applicant is of low type and the match quality equals 0 . Substituting $w^{\prime}$ using equation (5) gives,

$$
\Pi\left(x^{\prime}\right)=x^{\prime} \eta\left(x^{\prime}\right)\left[\frac{m \gamma^{h} \pi}{m \gamma^{h}+(1-m)}+(1-\pi) y^{m}\right]-\left[\frac{m \gamma^{h} \pi}{m \gamma^{h}+(1-m)}+(1-\pi)\right] x^{\prime} U_{h}^{*} .
$$

Differentiating with respect to $x^{\prime} \equiv x\left(w^{\prime} \mid U_{h}^{*}\right)$, implies that the following wage is optimal for the deviating firm,

$$
w^{\prime}=\frac{m \gamma^{h} \pi+\left[m \gamma^{h}+(1-m)\right](1-\pi) y^{m}}{m \gamma^{h} \pi+\left[m \gamma^{h}+(1-m)\right](1-\pi)} \frac{x^{\prime} e^{-x^{\prime}}}{1-e^{-x^{\prime}}} .
$$

The deviation considered above is for a given fraction of high-type workers $\gamma^{h}$ that apply to wage posting firms. But note that a wage-posting firm with a hiring threshold $\bar{y}=y^{m}$ can attract not only $\gamma^{h}$ but all high-type worker by offering epsilon more than other firms. Such a deviation is profitable, since it increases the expected productivity of the applicants at only epsilon cost. This is summarized in the following Lemma. 
Lemma 2 Wage-posting firms with hiring threshold $\bar{y}=y^{m}$ post the wage,

$$
w\left(y^{m}\right)=\frac{m \pi+(1-\pi) y^{m}}{m \pi+(1-\pi)} \frac{x\left(w \mid y^{m}\right) e^{-x\left(w \mid y^{m}\right)}}{1-e^{-x\left(w \mid y^{m}\right)}}
$$

and attract all suitable workers, i.e., $\gamma^{h}=1$.

Proof: See Appendix A.1.

In a directed search equilibrium all high-type workers must be indifferent about all of the wages posted, which implies the following equilibrium wage, worker utility and firm profits,

$$
\begin{aligned}
w\left(y^{m}\right) & =\frac{m \pi+(1-\pi) y^{m}}{m \pi+(1-\pi)} \frac{x\left(w \mid y^{m}\right) e^{-x\left(w \mid y^{m}\right)}}{1-e^{-x\left(w \mid y^{m}\right)}}, \\
U_{h}\left(w \mid y^{m}\right) & =\frac{m \pi+(1-\pi) y^{m}}{m \pi+(1-\pi)} e^{-x\left(w \mid y^{m}\right)}, \\
\Pi\left(w \mid y^{m}\right) & =\left[m \pi+(1-\pi) y^{m}\right]\left(1-e^{-x\left(w \mid y^{m}\right)}-x\left(w \mid y^{m}\right) e^{-x\left(w \mid y^{m}\right)}\right) .
\end{aligned}
$$

Consider now the second case where the deviating firm sets the hiring threshold such that only high-type applicants are hired, i.e., $\bar{y}^{\prime}=1$. The hiring threshold $\bar{y}^{\prime}=1$ implies that a randomly selected and high-type applicant will pass the interview and be hired with probability $\pi$. The wage-posting firm chooses $w^{\prime}$ to maximize profits, i.e.,

$$
w\left(U_{h}^{*}\right)=\arg \max _{w^{\prime}} x\left(w^{\prime} \mid U_{h}^{*}\right) \eta\left(x\left(w^{\prime} \mid U_{h}^{*}\right)\right) \pi\left(1-w^{\prime}\right) .
$$

Following the same steps as above it follows that in a directed search equilibrium all hightype workers must be indifferent about all of the wages posted, which implies the following equilibrium wage, worker utility and firm profits,

$$
\begin{aligned}
w(1) & =\frac{x(w \mid 1) e^{-x(w \mid 1)}}{1-e^{-x(w \mid 1)}}, \\
U_{h}(w \mid 1) & =\pi e^{-x(w \mid 1)}, \\
\Pi(w \mid 1) & =\pi\left(1-e^{-x(w \mid 1)}-x(w \mid 1) e^{-x(w \mid 1)}\right) .
\end{aligned}
$$

The following Lemma shows that for $(1-m) / y^{m}$ small enough firms choose to hire workers with a medium and high match quality, while for $(1-m) / y^{m}$ high enough firms only hire workers with a high match quality. The respective cutoff value is denoted by $C^{*}$.

Lemma 3 Wage-posting firms choose the hiring threshold $\bar{y}=y^{m}$ if and only if $(1-m) / y^{m}<$ $C^{*}$. Otherwise they choose the hiring threshold $\bar{y}=1 . C^{*}$ satisfies,

$$
\frac{1-\pi}{\pi}<C^{*}<\frac{1}{\pi}
$$


Proof: See Appendix A.2.

Lemma 3 determines for which values of $(1-m) / y^{m}$ wage-posting firms prefer a pooling strategy and hire applicants with a medium and high match quality $\left(\bar{y}=y^{m}\right)$ and for which they prefer a separating strategy and hire only applicants with a high match quality $(\bar{y}=1)$. The intuition is as follows. The ratio $(1-m) / y^{m}$ indicates the costs of pooling workers with a medium and high match quality. If the proportion of low-type workers $1-m$ is low and/or the productivity of a medium quality match $y^{m}$ high, the costs of pooling are low and it is worthwhile to hire workers with a medium match quality even if this policy will attract all low-type workers as implied by Lemma 1. If the proportion of low-type workers $1-m$ is high and/or the productivity of a medium quality match $y^{m}$ low, it is beneficial to separating workers by hiring only workers with a high match quality and detering low-type workers from applying. To put it in other words: The firm accepts a medium quality match if the productivity of this match is close to a high quality matches or if the probability of attracting a low type is low, i.e. if $1-m$ is low. If $1-m$ is high, the probability of attracting a low-type applicant is high, given the threshold $y^{m}$. In this case pooling is costly because the probability to have to reject a worker and remain unmatched is high.

The profit of wage-posting firms is therefore given by,

$$
\Pi_{w}= \begin{cases}\Pi(w \mid 1) & \text { if } \frac{1-m}{y^{m}} \geq C^{*}, \\ \Pi\left(w \mid y^{m}\right) & \text { if } \frac{1-m}{y^{m}}<C^{*}\end{cases}
$$

Next, we will derive the expected profit of wage-bargaining firms for the respective hiring thresholds and characterize the hiring threshold decision. If a wage-bargaining firm decides to hire applicants with medium and high match quality, i.e., $\bar{y}_{\varnothing}=y^{m}$, then we know, due to Lemma 1 , that either all or no low-type workers apply to wage-bargaining firms, i.e., $\gamma^{l} \in$ $\{0,1\}$. The probability that a wage-bargaining firm receives at least one applicant, given the expected number of applicants $x\left(w_{\varnothing} \mid y^{m}\right)$ defined in equation $(1)$, is equal to $\left(1-e^{-x\left(w_{\varnothing} \mid y^{m}\right)}\right)$. One of the applicants is picked randomly and interviewed. This randomly selected applicant draws a high or medium match quality with probability,

$$
\frac{m\left(1-\gamma^{h}\right)+(1-m)\left(1-\gamma^{l}\right)(1-\pi)}{m\left(1-\gamma^{h}\right)+(1-m)\left(1-\gamma^{l}\right)}
$$

and is then hired. Wages are conditional on match quality $y_{i} \in\left\{y^{m}, 1\right\}$. The expected profit of a wage-bargaining firm with a hiring threshold $\bar{y}_{\varnothing}=y^{m}$ is therefore given by,

$$
\begin{aligned}
\Pi\left(w_{\varnothing} \mid y^{m}\right)= & \left(1-e^{-x\left(w_{\varnothing} \mid y^{m}\right)}\right)(1-\beta) \\
& \times \frac{m\left(1-\gamma^{h}\right)\left(\pi+(1-\pi) y^{m}\right)+(1-m)\left(1-\gamma^{l}\right)(1-\pi) y^{m}}{m\left(1-\gamma^{h}\right)+(1-m)\left(1-\gamma^{l}\right)} .
\end{aligned}
$$


Note, that wages depend on the match quality and not on type of the worker. This is in contrast to Michelacci and Suarez (2006) who set the type of a worker equal to the output that the worker produces. This difference is crucial in understanding the differences in the equilibrium outcomes characterized below.

If a wage-bargaining firm decides to hire only applicants with a high match quality, i.e., $\bar{y}_{\varnothing}=1$, then only high-type workers apply. A randomly selected high-type applicant draws a high match quality with probability $\pi$ and is hired. The expected output is equal to 1 and the wage equal to $\beta$. This implies the following expected profit,

$$
\Pi\left(w_{\varnothing} \mid 1\right)=\left(1-e^{-x\left(w_{\varnothing} \mid 1\right)}\right)(1-\beta) \pi .
$$

Wage-bargaining firms choose the hiring threshold $\bar{y}_{\varnothing}$, which maximizes the expected profit, i.e., $\Pi_{\varnothing}=\max _{\bar{y}_{\varnothing} \in\left\{y^{m}, 1\right\}} \Pi\left(w_{\varnothing} \mid \bar{y}_{\varnothing}\right)$.

Vacancy creation (first stage): If wage-bargaining generates a profit higher than wageposting and is high enough to cover the cost of vacancy creation $k$, then only wage-bargaining will be offered. The respective number of vacancies $v_{\varnothing}$ created by wage-bargaining firms is given by,

$$
\Pi_{\varnothing}=k>\Pi_{w}
$$

where $x\left(w_{\varnothing} \mid \bar{y}_{\varnothing}\right)$ in equation $(1)$ determines the number of vacancies $v_{\varnothing}$. If wage-posting generates a profit higher than wage-bargaining and is high enough to cover the cost of vacancy creation $k$, then only wage-posting will be offered. The respective number of vacancies $v$ created by wage-bargaining firms is given by,

$$
\Pi_{w}=k>\Pi_{\varnothing}
$$

where $x(w \mid \bar{y})$ in equation (4) determines the number of vacancies $v$. If wage-posting and wage-bargaining generates the same profit and if the profit is high enough to cover the cost of vacancy creation $k$, then wage-posting and wage-bargaining will be offered. The respective number of vacancies $v$ and $v_{\varnothing}$ are given by,

$$
\Pi_{w}=\Pi_{\varnothing}=k,
$$

where $x(w \mid \bar{y})$ and $x\left(w_{\varnothing} \mid \bar{y}_{\varnothing}\right)$ in equations (4) and (1) determine the respective number of vacancies. 


\subsection{Equilibrium}

Definition: A labor market equilibrium is defined by the tuple $\left\{v, v_{\varnothing}, \gamma^{h}, \gamma^{l}, w, w_{\varnothing}, \bar{y}, \bar{y}_{\varnothing}\right\}$ such that the following holds. Wage-posting firms offer the wage $w(1)$ specified in equation (11) and choose the hiring threshold $\bar{y}=1$ if $(1-m) / y^{m} \geq C^{*}$, and offer the wage $w\left(y^{m}\right)$ specified in equation (8) and choose the hiring threshold $\bar{y}=y^{m}$ if $(1-m) / y^{m}<C^{*}$. Wagebargaining firms pay a wage $w_{\varnothing}=\beta y_{i}$ and choose the hiring threshold $\bar{y}_{\varnothing}$ such that profits are maximized, i.e., $\Pi_{\varnothing}=\max _{\bar{y}_{\varnothing} \in\left\{y^{m}, 1\right\}} \Pi\left(w_{\varnothing} \mid \bar{y}_{\varnothing}\right)$. If the market utility from applying at a firm is zero workers will not apply. If the market utility is positive for high-type workers, they apply at wage-bargaining (wage-posting) firms, if the expected utility $U_{h}\left(w_{\varnothing} \mid \bar{y}_{\varnothing}\right)\left(U_{h}(w \mid \bar{y})\right)$ is at least as high as the market utility $U_{h}^{*}$. If they are indifferent about applying to a wageposting or a wage-bargaining firm they use a mixed application strategy $\gamma^{h}$. If wage-posting firms offer a hiring threshold $\bar{y}=y^{m}$, all low-type workers apply there according to Lemma 1, i.e., $\gamma^{l}=1$ if $\bar{y}=y^{m}$. Low-type workers only apply at wage-bargaining firms that offer a hiring threshold $\bar{y}_{\varnothing}=y^{m}$, if no wage-posting firms exist, i.e., $v=0$, or if wage-posting firms offer a hiring threshold $\bar{y}=1$. The creation of vacancies is characterized in equations (17) to (19).

Two parameters are crucial to characterize the type of equilibrium that exists, $(1-m) / y^{m}$ the ratio of the number of low-type workers to the productivity of jobs with a medium match quality and $\beta$ the bargaining power of workers. We will discuss the different types of equilibria for three different $(1-m) / y^{m}$-parameter regions $(1-m) / y^{m}<C^{*}, C^{*}<(1-m) / y^{m}<$ $C^{* *}$ and $(1-m) / y^{m}>C^{* *}$.

Pure wage-posting equilibrium for $(1-m) / y^{m}>C^{* *}$ : For $(1-m) / y^{m}>C^{* *}$ the number of low-type workers $1-m$ is very high and/or the productivity of jobs with a medium match quality very low. It is therefore too costly to hire workers with a medium match quality and attract low-type workers. Thus, firms prefer to separate low- from high-type workers as shown in in Appendix A.3 by posting a fixed wage and committing to hire only workers with a high match quality, i.e., choosing a hiring threshold $\bar{y}=1$.

Equilibrium regions for $C^{*}<(1-m) / y^{m}<C^{* *}$ : We know from Lemma 3 that wageposting firms, if they exist, will choose a hiring threshold $\bar{y}=1$. This fact also implies that wage-bargaining with a hiring threshold $\bar{y}_{\varnothing}=1$ can never exist. To see this, note that by posting the wage $w(1)$ according to equation (11) and by choosing a hiring threshold $\bar{y}^{\prime}=1$, the deviating firms can offer high-type workers a higher expected utility $U_{h}\left(w^{\prime} \mid 1\right)>U_{h}\left(w_{\varnothing} \mid 1\right)$ 
for any $\beta \neq w\left(\bar{y}^{\prime}\right)$ as shown by Hosios (1990). High-type workers will therefore only apply at wage-posting firms, which implies that wage-bargaining with $\bar{y}_{\varnothing}=1$ cannot exist.

Three types of equilibria exist: pure wage-posting with $\bar{y}=1$, pure wage-bargaining with $\bar{y}_{\varnothing}=y^{m}$, and a coexistence equilibrium with both types. The region in which each of these equilibria exists depends on the worker's bargaining power $\beta$. To characterize the different regions we denote by $\beta^{*}=x_{\varnothing} e^{-x \varnothing} /\left(1-e^{-x \varnothing}\right)$ the bargaining power that maximizes hightype worker's utility $U_{h}\left(w_{\varnothing} \mid y^{m}\right)$ subject to the vacancy creation condition, i.e., the bargaining power that satisfies the Hosios condition.

We define cutoff values $\underline{b}$ and $\bar{b}$ for the bargaining power parameter with $\underline{b}<\beta^{*}<\bar{b}$, such that for a bargaining power parameter between $\underline{b}$ and $\bar{b}$ a pure bargaining equilibrium exists and at $\underline{b}$ and $\bar{b}$ the economy switches to the coexistence equilibrium. This means, if the bargaining power is equal to $\underline{b}$ or $\bar{b}$ high-type workers are indifferent about wage-bargaining and wage-posting, i.e., $U_{h}\left(w_{\varnothing} \mid y^{m}\right)=U_{h}(w \mid 1)$, both wage-posting and wage-bargaining are equally profitable and satisfy the vacancy creation condition, i.e., $\Pi\left(w_{\varnothing} \mid y^{m}\right)=\Pi\left(w^{\prime} \mid 1\right)=k$, and all high-type workers apply at wage-bargaining firms, i.e., $\gamma^{h}=0$. When $\beta<\underline{b}$ or $\bar{b}<\beta$ some high-type workers apply for posting firms, i.e., $\gamma^{h}>0$. We also define cutoff values $\underline{p}$ and $\bar{p}$ where the equilibrium switches from the coexistence equilibrium to the pure posting equilibrium. Thus $\underline{p}$ and $\bar{p}$ are the lower and the upper bound of the bargaining power parameters that ensure equal utility for high-type workers $U_{h}\left(w_{\varnothing} \mid y^{m}\right)=U_{h}(w \mid 1)$ and $\Pi\left(w_{\varnothing} \mid y^{m}\right)=\Pi(w \mid 1)=k$. When the bargaining power parameter is outside the upper and lower bounds $\left(\beta<\underline{p}\right.$ or $\bar{p}<\beta$ ), all high-type workers apply for posting firms, i.e., $\gamma^{h}=1$.

Theorem 1 For $C^{*}<(1-m) / y^{m}<C^{* *}$ a directed search equilibrium always exists and is unique. There are critical values $0<\underline{p}<\underline{b}<\beta^{*}<\bar{b}<\bar{p}<1$ such that there exists for $\beta \in$ $[\underline{b}, \bar{b}]$ a pure wage-bargaining equilibrium with hiring threshold $\bar{y}_{\varnothing}=y^{m}$, for $\beta \in(\underline{p}, \underline{b}) \cup(\bar{b}, \bar{p})$ a coexistence equilibrium with wage-posting and wage-bargaining and hiring thresholds $\bar{y}=1$ and $\bar{y}_{\varnothing}=y^{m}$, and for $\beta \in(0, \underline{p}] \cup[\bar{p}, 1)$ a pure wage-posting equilibrium with hiring thresholds $\bar{y}=1$.

Proof: See Appendix A.3.

If worker's bargaining power is close to satisfying the Hosios condition, i.e., $\beta \in[\underline{b}, \bar{b}]$, wage-bargaining dominates wage-posting, because wage-bargaining allows firms to offer different wages to workers with a medium and a high match quality and the matching inefficiency associated with wage-bargaining is low. If a worker's bargaining power is further away from satisfying the Hosios condition wage-bargaining becomes less attractive, since these firms are 
not able to optimally trade off the hiring probability and wages. This search inefficiency inherent in wage-bargaining decreases the profit of wage-bargaining firms and triggers entry of wage-posting firms if $\beta \in(\underline{p}, \underline{b}) \cup(\bar{b}, \bar{p})$. Wage-bargaining and wage-posting firms coexist even though wage-posting is efficient in terms of balancing the matching probability and the wage. But wage-posting firms choose to hire only workers with a high match quality, if the measure of low-type workers is high or the productivity of the medium match quality low, i.e., $(1-m) / y^{m}>C^{*}$. This implies that high-type workers find it less attractive to apply at wage-posting firms, since wage-posting firms will turn them down if match quality has a medium value. This enables coexistence. If a worker's bargaining power takes on extreme cases, i.e., $\beta \in(0, \underline{p}] \cup[\bar{p}, 1)$, the search inefficiency of wage-bargaining is so severe that wage-posting dominates. This is shown in Figure 3.

Figure 3: Equilibrium regions

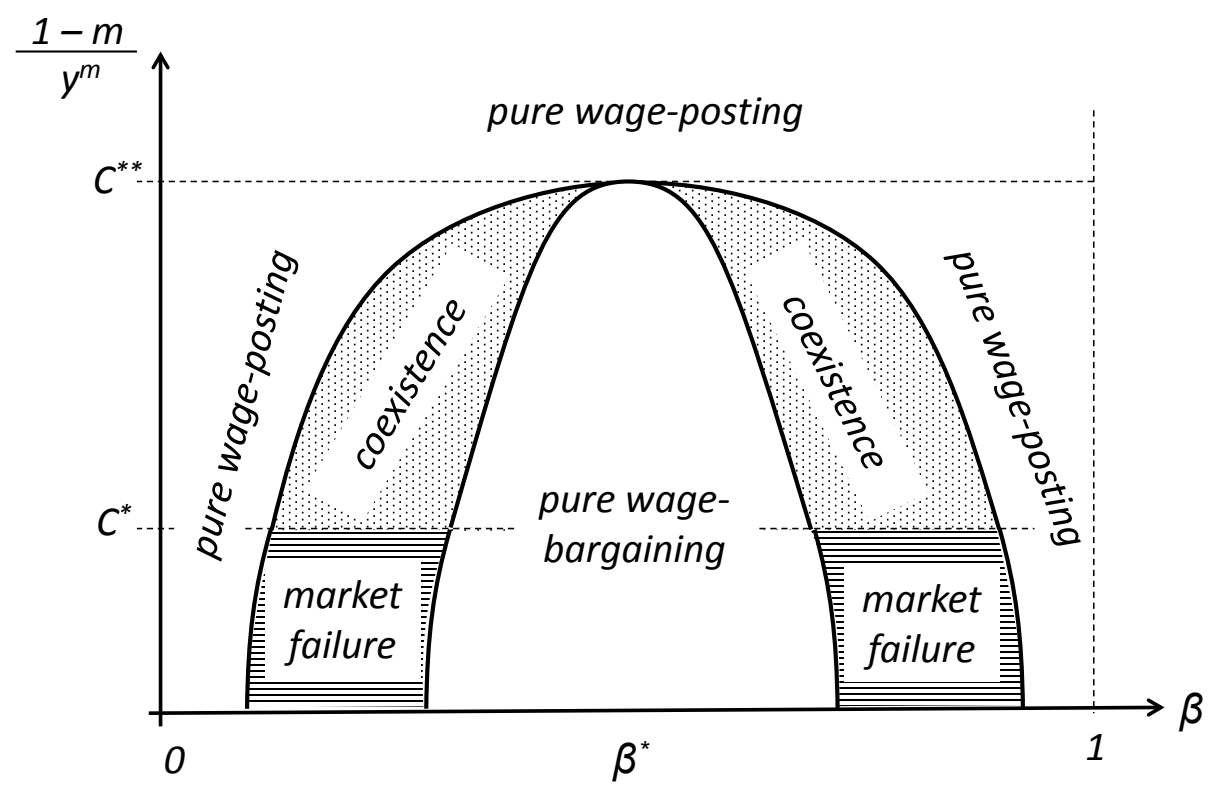

Equilibrium regions for $(1-m) / y^{m}<C^{*}$ : Lemmas 1, 2, and 3 imply that wage-posting firms, if they exist, will attract all low- and high-type workers. This also implies that it is impossible for wage-posting and wage-bargaining firms to coexist. Depending on worker's bargaining power there will be regions in which only wage-bargaining firms with a hiring threshold $\bar{y}_{\varnothing}=y^{m}$ exist and regions in which only wage-posting firms with a hiring threshold $\bar{y}=y^{m}$ exist. In the middle region adverse selection leads to market failure.

Theorem 2 For $(1-m) / y^{m}<C^{*}$ a directed search equilibrium does not always exist. Where it exists it is unique. There are critical values $0<p^{\prime}<\underline{b}^{\prime}<\beta^{*}<\bar{b}^{\prime}<\bar{p}^{\prime}<1$ 
such that for $\beta \in\left[\underline{b}^{\prime}, \bar{b}^{\prime}\right]$ there exists a pure wage-bargaining equilibrium with hiring threshold $\bar{y}_{\varnothing}=y^{m}$, and for $\beta \in\left(0, \underline{p}^{\prime}\right] \cup\left[\bar{p}^{\prime}, 1\right)$ a pure wage-posting equilibrium with hiring thresholds $\bar{y}=y^{m}$. For $\beta \in\left(\underline{p}^{\prime}, \underline{b}^{\prime}\right) \cup\left(\bar{b}^{\prime}, \bar{p}^{\prime}\right)$ adverse selection leads to market failure.

Proof: See Appendix A.4.

No equilibrium exists for bargaining power parameters $\beta \in\left(\underline{p}^{\prime}, \underline{b}^{\prime}\right) \cup\left(\bar{b}^{\prime}, \bar{p}^{\prime}\right)$. The intuition is as follows. From Lemma 1 we know that posting a unique wage with a hiring threshold $y^{m}$ is associated with adverse selection. Wage-posting firms that attract all low-type workers therefore try to hire as many high-type workers as possible (as stated in Lemma 2) in order to decrease the effect of adverse selection. They can do this as long as the worker's bargaining power is so extreme that wage-bargaining is never optimal. However, as the search inefficiency associated with wage-bargaining becomes smaller (as the bargaining power gets closer to the Hosios condition), it is profitable for firms to deviate and offer to bargain with a hiring threshold $\bar{y}_{\varnothing}=y^{m}$. This has the advantage of attracting only high-type workers without the cost of having to reject the high-type applicants with a medium match quality. Thus, no equilibrium exists, since deviating in the presence of a wage-posting firm attracts only hightype workers and therefore generates an expected deviating profit $\Pi^{\prime}\left(w_{\varnothing} \mid y^{m}\right)$ greater than the profit $\Pi\left(w_{\varnothing} \mid y^{m}\right)$ that a firm can obtain in a pure wage-bargaining equilibrium, where it attracts also low-type workers.

\subsection{Interpreting the Empirical Results}

In our empirical analysis we showed that the number of applicants does not differ systematically between wage-posting and wage-bargaining firms, but wage-posting firms attract more suitable workers than wage-bargaining firms. Let us now view these results in the light of our theoretical model.

Fraction of suitable workers: In the theoretical model, we have low- and high-type workers with different expected match quality. Match quality can take three values "low", "medium" and "high". In an equilibrium where both wage-posting and wage-bargaining firms coexist, wage-posting firms hire only workers with a high match quality while wage-bargaining firms hire workers with a high and medium match quality. Thus, only high-type workers apply at wage-posting firms, while low- and high-type workers apply at wage-bargaining firms.

To relate our model to the empirical result, we define the fraction of suitable workers in accordance with the hiring threshold of wage-posting and wage-bargaining firms, i.e., $\bar{y}=1$ 
and $\bar{y}_{\varnothing}=y^{m}$. In an equilibrium where both wage-posting and wage-bargaining firms coexist, wage-posting firms will only classify applicants with a high match quality as suitable. The respective fraction of suitable workers among all applicants is hence given by $\pi$ the probability that a high-type worker draws a high match quality. Wage-bargaining firms will classify all applicants with a high and medium match quality as suitable. The respective fraction of suitable workers among all (high and low-type) applicants is,

$$
\frac{m\left(1-\gamma^{h}\right)+(1-m)(1-\pi)}{m\left(1-\gamma^{h}\right)+(1-m)}
$$

where $m\left(1-\gamma^{h}\right)$ equals the fraction of high-type workers that apply to wage-barginings firms (who always have a high or medium match quality) and $(1-m)(1-\pi)$ the fraction of lowtype workers that draw a medium match quality. The necessary condition for wage-posting firms to attract more suitable applicants is given by,

$$
\frac{(1-m)}{m\left(1-\gamma^{h}\right)+(1-m)}>\frac{1-\pi}{\pi} \text {. }
$$

A sufficient condition is given by $(1-m)>(1-\pi) / \pi\left(\gamma^{h}=0\right)$. If this condition holds, our theory predicts that wage-posting firms with a hiring threshold $\bar{y}=1$ will report more suitable applicants than wage-bargaining firms with a hiring threshold $\bar{y}_{\varnothing}=y^{m}$.

Number of applicants: If both wage-posting and wage-bargaining firms coexist, our theory predicts that workers' bargaining power should be not too far from satisfying the Hosios condition. Theoretically, it can be above or below the value $\beta^{*}$, which satisfies the Hosios condition as shown in Figure 3. Our empricial result that wage-posting and wage-bargaining firms attract on average the same number of workers predicts that workers' bargaining power $\beta$ has to be below $\beta^{*}$. To see this consider the utility high-type workers that apply at wageposting and wage-bargaining firms. If wage-posting and wage-bargaining coexist, high-type workers have to be indifferent, which implies,

$$
U_{h}\left(w_{\varnothing} \mid y^{m}\right)=U_{h}(w \mid 1) \Longleftrightarrow \frac{1-e^{-x_{\varnothing}}}{x_{\varnothing}}\left(\pi+(1-\pi) y^{m}\right) \beta=\pi e^{-x^{h}} .
$$

If the number of applicants is on average the same, we get $x_{\varnothing}=x^{h}$, which implies,

$$
\frac{1-e^{-x_{\varnothing}}}{x_{\varnothing} e^{-x_{\varnothing}}} \beta\left(1+\frac{1-\pi}{\pi} y^{m}\right)=1 .
$$

This rearranged indifference condition can only hold if workers' bargaining power is below the Hosios condition, i.e., if

$$
\beta<\beta^{*}=\frac{x_{\varnothing} e^{-x_{\varnothing}}}{1-e^{-x_{\varnothing}}} .
$$


The intuition for this result is as follows. In the coexistence equilibrium wage-bargaining firms pay $\beta$ to workers with a high match quality and $\beta y^{m}$ to workers with a medium match quality, while wage-posting firms pay a wage $w=x^{h} e^{-x^{h}} /\left(1-e^{-x^{h}}\right)$ to high match quality workers and reject workers with a medium match quality. If the number of applicants are equal, i.e., $x_{\varnothing}=x^{h}$, then the probability that a high-type workers is selected for the interview is the same at both types of firms. If workers' bargaining $\beta$ were equal to $\beta^{*}$, high-type workers with a high match quality at wage-bargaining firms would get the same wage as workers at wageposting firms. In addition they would get $\beta y^{m}$ if they draw a medium match quality, while high-type workers, who draw a medium match quality at wage-posting firms, are rejected and get zero. Thus, high-type workers would prefer wage-bargaining firms. If, however, $\beta<\beta^{*}$ high type workers tend to find wage-posting firms more attractive, which tends to decrease the number of high-type applicants at wage-bargaining firms. However, since wagebargaining firms attract low- and high-type workers, while wage-posting firms attract only high-type workers, we get on average the same number of applicants at wage-posting and wage-bargaining firms.

\section{Conclusion}

We use the German Job Vacancy Survey, a representative establishment dataset collected by the Federal Employment Agency in Germany, which contains numerous questions regarding the recruitment process, to investigate whether firms are able to attract more suitable applicants by using wage-posting compared to wage-bargaining. Contrary to the theoretical prediction made by Michelacci and Suarez (2006), we find that wage-bargaining decreases the share of suitable applicants by 5.1 percentage points. If we differentiate the sample by job qualification requirements, we find that the effect is driven by jobs requiring intermediate and higher qualifications. The effect for jobs with no qualification requirement is, as expected, insignificant and close to zero.

In the second part of the paper we modify the directed search model with asymmetric information and incomplete contracts used by Michelacci and Suarez (2006) to reconcile the theory with the empirical evidence. The first difference is that we break the perfect correlation between worker types and match quality. The perfect correlation in Michelacci and Suarez (2006) implies that wage-bargaining is equivalent to output-related pay. In our model, wagebargaining firms pay fixed wages conditional on the revealed match quality that is only imperfectly correlated with the type of a worker. The second difference is that firms in our 
framework can reject workers with a match quality below a certain threshold. We show that wage-posting and wage-bargaining firms coexist if separating workers with different expected match quality is not too costly for wage-posting firms and if the bargaining power is not too far away from satisfying the Hosios condition. In such an equilibrium wage-posting firms hire only workers with a high match quality and wage-bargaining firms hire workers with a high and a medium match quality. 


\section{References}

Abbring, J. H., and J. C. van Ours (1994): 'Sequential or non-sequential employers' search?," Economics Letters, 44(3), 323-328.

Acemoglu, D., And R. Shimer (1999): "Holdups and Efficiency with Search Frictions," International Economic Review, 40(4), 827-849.

Albrecht, J., P. Gautier, and S. Vroman (2012): "A note on Peters and Severinov, Competition among sellers who offer auctions instead of prices," Journal of Economic Theory, 147(1), 389-392. forthcoming.

Bester, H. (1993): "Bargaining versus Price Competition in Markets with Quality Uncertainty," American Economic Review, 83(1), 278-88.

Brencic, V., AND J. B. NorRis (2010): "Do employers change job offers in their online job ads to facilitate search?," Economics Letters, 108(1), 46-48.

Brenzel, H., H. Gartner, and C. Schnabel (2014): "Wage bargaining or wage posting? Evidence from the employers' side," Labour Economics, 29(C), 41-48.

Burdett, K., S. Shi, And R. Wright (2001): "Pricing and Matching with Frictions," Journal of Political Economy, 109(5), 1060-1085.

Camera, G., and A. Delacroix (2004): "Trade Mechanism Selection in Markets with Frictions," Review of Economic Dynamics, 7(4), 851-868.

Carrillo-Tudela, C., And L. KaAs (2013): "Worker Mobility in a Search Model with Adverse Selection," Working paper, Department of Economics, University of Konstanz.

Delacroix, A., And S. Shi (2013): "Pricing and signaling with frictions," Journal of Economic Theory, 148(4), 1301-1332.

Dohmen, T., And A. Falk (2011): "Performance Pay and Multidimensional Sorting: Productivity, Preferences, and Gender," American Economic Review, 101(2), 556-90.

Ellingsen, T., And A. Rosen (2003): "Fixed or Flexible? Wage-setting in Search Equilibrium," Economica, 70(278), 233-250.

Guasch, J. L., And A. Weiss (1982): "An Equilibrium Analysis of Wage-Productivity Gaps," Review of Economic Studies, 49(4), 485-97.

Guerrieri, V., R. Shimer, and R. Wright (2010): "Adverse Selection in Competitive Search Equilibrium," Econometrica, 78(6), 1823-1862.

Hall, R. E., And A. B. Krueger (2012): "Evidence on the Incidence of Wage Posting, Wage Bargaining, and On-the-Job Search," American Economic Journal: Macroeconomics, $4(4), 56-67$.

Hosios, A. J. (1990): "On the Efficiency of Matching and Related Models of Search and Unemployment," Review of Economic Studies, 57(2), 279-98. 
Lazear, E. P. (2000): "Performance Pay and Productivity," American Economic Review, $90(5), 1346-1361$.

McAfee, R. P. (1993): "Mechanism Design by Competing Sellers," Econometrica, 61(6), $1281-1312$.

Menzio, G. (2007): "A Theory of Partially Directed Search," Journal of Political Economy, $115(5), 748-769$.

Michaels, E., H. Handfield-Jones, and B. Axelrod (2001): The war for talent. Harvard Business Press.

Michelacci, C., and J. Suarez (2006): "Incomplete Wage Posting," Journal of Political Economy, 114(6), 1098-1123.

Moen, E. R. (1997): "Competitive Search Equilibrium," Journal of Political Economy, $105(2), 385-411$.

Nalebuff, B., and D. Scharfstein (1987): "Testing in Models of Asymmetric Information," Review of Economic Studies, 54(2), 265-77.

Oyer, P., And S. Schaefer (2005): "Why do some firms give stock options to all employees?: An empirical examination of alternative theories," Journal of Financial Economics, 76(1), 99-133.

Peters, M. (1991): "Ex Ante Price Offers in Matching Games Non-steady States," Econometrica, 59(5), 1425-54.

Peters, M., And S. Severinov (1997): "Competition among Sellers Who Offer Auctions Instead of Prices," Journal of Economic Theory, 75(1), 141-179.

Salop, J., and S. SAlop (1976): "Self-Selection and Turnover in the Labor Market," The Quarterly Journal of Economics, 90(4), 619-27.

VAN OuRs, J., ANd G. Ridder (1992): "Vacancies and the Recruitment of New Employees," Journal of Labor Economics, 10(2), 138-55.

WANG, R., And A. Weiss (1998): "Probation, layoffs, and wage-tenure profiles: A sorting explanation," Labour Economics, 5(3), 359-383. 


\section{A Appendix: Proofs}

\section{A.1 Proof of Lemma 2}

The profits of wage-posting firms deviating to $w^{d}\left(y^{m} \mid \gamma^{h}=1\right)$ is given by

$$
\Pi\left(w^{d} \mid y^{m}\right)=\left[m \pi+(1-\pi) y^{m}\right]\left(1-e^{-x\left(w^{d} \mid y^{m}\right)}-x\left(w^{d} \mid y^{m}\right) e^{-x\left(w^{d} \mid y^{m}\right)}\right),
$$

where $x\left(w^{d} \mid y^{m}\right)$ satisfies that high-type workers receive the same market utility, i.e., $U_{h}\left(w^{d} \mid y^{m}, \gamma^{h}=1\right)=$ $U_{h}\left(w^{\prime} \mid y^{m}, \gamma^{h}\right)$

$$
\frac{m \pi+(1-\pi) y^{m}}{m \pi+(1-\pi)} e^{-x\left(w^{d} \mid y^{m}\right)}=\frac{m \gamma^{h} \pi+\left[m \gamma^{h}+(1-m)\right](1-\pi) y^{m}}{m \gamma^{h} \pi+\left[m \gamma^{h}+(1-m)\right](1-\pi)} e^{-x\left(w^{\prime} \mid y^{m}\right)} .
$$

The last equation implies $x\left(w^{d} \mid y^{m}\right)>x\left(w^{\prime} \mid y^{m}\right)$. Comparing the deviating profit $\Pi\left(w^{d} \mid y^{m}, \gamma^{h}=1\right)$ with $\Pi\left(w^{\prime} \mid y^{m}\right)$ implies,

$$
\begin{aligned}
& \Pi\left(w^{\prime} \mid y^{m}\right)-\Pi\left(w^{d} \mid y^{m}, \gamma^{h}=1\right) \\
= & \frac{m \gamma^{h} \pi+\left[m \gamma^{h}+(1-m)\right](1-\pi) y^{m}}{m \gamma^{h}+(1-m)}\left(1-e^{-x\left(w^{\prime} \mid y^{m}\right)}-x\left(w^{\prime} \mid y^{m}\right) e^{-x\left(w^{\prime} \mid y^{m}\right)}\right) \\
& -\left[m \pi+(1-\pi) y^{m}\right]\left(1-e^{-x\left(w^{d} \mid y^{m}\right)}-x\left(w^{d} \mid y^{m}\right) e^{-x\left(w^{d} \mid y^{m}\right)}\right) \\
< & 0,
\end{aligned}
$$

where the last equality follows from $x\left(w^{d} \mid y^{m}\right)>x\left(w^{\prime} \mid y^{m}\right)$ and

$$
\frac{m \gamma^{h} \pi+\left[m \gamma^{h}+(1-m)\right](1-\pi) y^{m}}{m \gamma^{h}+(1-m)}-\left[m \pi+(1-\pi) y^{m}\right]<0 .
$$

It follows that deviating to $\gamma^{h}=1$ is always profitable for any $\gamma^{h} \in[0,1)$. QED

\section{A.2 Proof of Lemma 3}

It will turn out to be useful to define

$$
C \equiv \frac{1-m}{y^{m}} .
$$

Under the assumption that an equilibrium exists we will show that wage-posting firms choose the hiring threshold $\bar{y}=y^{m}$ if and only if $C<C^{*}$ and the hiring threshold $\bar{y}=1$ if and only if $C \geq C^{*}$, where $C^{*} \in\left(\frac{1-\pi}{\pi}, \frac{1}{\pi}\right)$. To simplify the notation we define $x^{m} \equiv x\left(w \mid y^{m}\right)$ and $x^{h} \equiv x(w \mid 1)$.

We start with showing that for $C \leq \frac{1-\pi}{\pi}$ firms will choose a hiring threshold $\bar{y}=y^{m}$. Suppose firms choose the hiring threshold $\bar{y}=1$ if $C \leq \frac{1-\pi}{\pi}$. Consider the profit of a deviating firm that chooses the hiring threshold $\bar{y}^{\prime}=y^{m}$ compared to the profit of choosing the hiring threshold $\bar{y}=1$. It follows from equation (10), Lemma 2 and (13) that

$$
C \leq \frac{1-\pi}{\pi} \Longleftrightarrow m+\frac{1-\pi}{\pi} y^{m}=\frac{1-e^{-x^{h}}-x^{h} e^{-x^{h}}}{1-e^{-x^{m}}-x^{m} e^{-x^{m}}} \geq 1 .
$$

Thus $e^{-x^{h}} \leq e^{-x^{m}}$. But this implies that all high-type workers apply to the deviating firm, i.e.,

$$
\frac{U_{h}(w \mid 1)}{U_{h}\left(w \mid \underline{s}^{m}\right)}=\frac{m \pi+(1-\pi)}{m+\frac{1-\pi}{\pi} y^{m}} \frac{e^{-x^{h}}}{e^{-x^{m}}}<1,
$$


since $m+\frac{1-\pi}{\pi} y^{m} \geq 1$ by assumption $C \leq \frac{1-\pi}{\pi}$.

We now show that for $C \geq \frac{1}{\pi}$ firms will choose a hiring threshold $\bar{y}=1$. Suppose firms choose the hiring threshold $\bar{y}=y^{m}$ if $C \geq \frac{1}{\pi}$. Suppose a deviating firm chooses the hiring threshold $\bar{y}^{\prime}=1$ and offers high-type workers a utiliy that makes them indifferent, i.e., $U_{h}(w \mid 1)=U_{h}\left(w \mid y^{m}\right)$. Then $U_{h}(w \mid 1)=U_{h}\left(w \mid y^{m}\right)$ implies $x^{h} \geq x^{m}$ since,

$$
\frac{e^{-x^{h}}}{e^{-x^{m}}}=\frac{m+\frac{1-\pi}{\pi} y^{m}}{m \pi+(1-\pi)} \leq 1 \Longleftrightarrow C \geq \frac{1}{\pi} .
$$

But the deviating firm makes higher profits, i.e.,

$$
\begin{aligned}
& \Pi\left(w \mid y^{m}\right)-\Pi(w \mid 1) \\
= & {\left[m \pi+(1-\pi) y^{m}\right]\left(1-e^{-x^{m}}-x^{m} e^{-x^{m}}\right)-\pi\left(1-e^{-x^{h}}-x^{h} e^{-x^{h}}\right) } \\
= & {\left[m \pi+(1-\pi) y^{m}\right] e^{-x^{m}}\left(\frac{1-e^{-x^{m}}-x^{m} e^{-x^{m}}}{e^{-x^{m}}}-\frac{1}{m \pi+(1-\pi)} \frac{1-e^{-x^{h}}-x^{h} e^{-x^{h}}}{e^{-x^{h}}}\right) } \\
< & 0,
\end{aligned}
$$

where the last equality follows from using $U_{h}(w \mid 1)=U_{h}\left(w \mid y^{m}\right)$.

Consider now the case where $C \in\left(\frac{1-\pi}{\pi}, \frac{1}{\pi}\right)$. We show that there exists a $C^{*} \in\left(\frac{1-\pi}{\pi}, \frac{1}{\pi}\right)$ such that $\Pi(w \mid 1)=\Pi\left(w \mid y^{m}\right)=k$ and $U_{h}(w \mid 1)=U_{h}\left(w \mid y^{m}\right)$ and that firms choose the hiring threshold $\bar{y}=y^{m}$ if and only if $C<C^{*}$ and the hiring threshold $\bar{y}=1$ if and only if $C \geq C^{*}$. We can use the definition of $C$ to define the function $m(C)=1-y^{m} C$ for any $C \in\left(\frac{1-\pi}{\pi}, \frac{1}{\pi}\right)$. The utility difference between applying to wage-posting firms with hiring threshold $\bar{y}=y^{m}$ and $\bar{y}=1$ is given by,

$$
D(C)=U_{h}\left(w \mid y^{m}\right)-U_{h}(w \mid 1)=\frac{1-y^{m} C+\frac{1-\pi}{\pi} y^{m}}{1-y^{m} C+\frac{1-\pi}{\pi}} e^{-x^{m}}-\pi e^{-x^{h}} .
$$

Note that $x^{m}$ and $x^{h}$ are implicitly defined by the respective vacancy creation conditions. Thus $x^{m}$ depends on $m(C)$, but $x^{h}$ is independent from $m(C)$. Evaluated at $C=\frac{1-\pi}{\pi}$, which implies $x^{h}=x^{m}$ according to $\Pi(w \mid 1)=\Pi\left(w \mid y^{m}\right)$, gives,

$$
D\left(\frac{1-\pi}{\pi}\right)=\left(\frac{1}{m \pi+(1-\pi)}-1\right) \pi e^{-x^{h}}>0
$$

Evaluated at $C=\frac{1}{\pi}$, which implies $x^{h}<x^{m}$ according to $\Pi(w \mid 1)=\Pi\left(w \mid y^{m}\right)$, gives,

$$
\begin{aligned}
D\left(\frac{1}{\pi}\right) & =\frac{m+(1-\pi)(1-m)}{m \pi+(1-\pi)} \pi e^{-x^{m}}-\pi e^{-x^{h}} \\
& =\pi\left(e^{-x^{m}}-e^{-x^{h}}\right)<0 .
\end{aligned}
$$

Since $D(C)$ is continuous in $C$, it follows that there exists a $C^{*} \in\left(\frac{1-\pi}{\pi}, \frac{1}{\pi}\right)$ with $D\left(C^{*}\right)=0$. The fact that

$$
\begin{aligned}
& \frac{\partial D(C)}{\partial C} \\
= & \frac{-y^{m}\left[1-y^{m} C+\frac{1-\pi}{\pi}\right]+y^{m}\left[1-y^{m} C+\frac{1-\pi}{\pi} y^{m}\right]}{\left[1-y^{m} C+\frac{1-\pi}{\pi}\right]^{2}} e^{-x^{m}}-\frac{1-y^{m} C+\frac{1-\pi}{\pi} y^{m}}{1-y^{m} C+\frac{1-\pi}{\pi}} e^{-x^{m}} \frac{d x^{m}}{d C} \\
= & -\frac{\frac{1-\pi}{\pi}\left[1-y^{m}\right]}{\left[1-y^{m} C+\frac{1-\pi}{\pi}\right]^{2}} y^{m} e^{-x^{m}}-\frac{y^{m}}{1-y^{m} C+\frac{1-\pi}{\pi}} \frac{1-e^{-x^{m}}-x^{m} e^{-x^{m}}}{x^{m}}<0
\end{aligned}
$$


where $d x^{m} / d C$ is obtained by implicitly differentiating

$$
\Pi\left(w \mid y^{m}\right)=\left[m(C) \pi+(1-\pi) y^{m}\right]\left(1-e^{-x^{m}}-x^{m} e^{-x^{m}}\right)=k .
$$

i.e.,

$$
\frac{d x^{m}}{d C}=\frac{\pi y^{m}\left(1-e^{-x^{m}}-x^{m} e^{-x^{m}}\right)}{\left[\pi-C \pi y^{m}+(1-\pi) y^{m}\right] x^{m} e^{-x^{m}}}>0 .
$$

This implies that $C^{*}$ is unique. Since $D(C)>0$ for $C<C^{*}$ and $D(C) \leq 0$ for $C \geq C^{*}$ it follows that firms choose the hiring threshold $\bar{y}=y^{m}$ if and only if $C<C^{*}$ and the hiring threshold $\bar{y}=1$ if and only if $C \geq C^{*}$. $Q E D$

\section{A.3 Proof of Theorem 1}

Given the application decision of high-type workers a certain recruitment policy (wage-posting or wage-bargaining) or policy mix (coexistence) only exists if it can offer the highest utility for high-type workers. The proof is therefore based on showing under which parameter values which recruitment policy can offer the highest utility for high-type workers taking the vacancy creation condition into account. To simplify the notation we define $x_{\varnothing} \equiv x\left(w_{\varnothing} \mid y^{m}\right)$, $x^{m} \equiv x\left(w \mid y^{m}\right)$ and $x^{h} \equiv x(w \mid 1)$.

Given $(1-m) / y^{m} \geq C^{*}$ Lemma 3 implies that wage-posting firms will choose a hiring threshold $\bar{y}=1$ (if they exist). The utility level that wage-posting firms can offer to suitable workers is independent of the existence of wage-bargaining and given by

$$
U_{h}(w \mid 1)=\pi e^{-x^{h}},
$$

where $x^{h}$ is implicitly defined by the vacancy creation condition,

$$
\Pi(w \mid 1)=\pi\left(1-e^{-x^{h}}-x^{h} e^{-x^{h}}\right)=k,
$$

where the assumption that $k$ is sufficiently small implies $k<\pi$. Note that the utility level $U_{h}(w \mid 1)$ is independent of $C=(1-m) / y^{m}$ and equals the equilibrium utility in case of a pure wage-posting equilibirum and the deviation utility in case of a pure wage-bargaining equilibrium.

Let us first consider the existence of a pure wage-bargaining equilibrium. Lemma 3 and the Hosios condition imply that it cannot be optimal to choose wage-bargaining with a hiring threshold $\bar{y}_{\varnothing}=1$, since there always exists a profitable deviation to wage-posting with $\bar{y}=1$. We therefore only need to consider wage-bargaining with a hiring threshold $\bar{y}_{\varnothing}=y^{m}$. Since we consider a pure wage-bargaining equilibrium all high- and low-type workers will in equilibrium apply to wage-bargaining firms, i.e., $\gamma^{h}=0$ and $\gamma^{l}=0$. To consider under which condition a deviation to wage-posting with hiring threshold $\bar{y}=1$ is optimal let us define

$$
\begin{aligned}
\Phi(\beta) & =U_{h}\left(w_{\varnothing} \mid y^{m}\right)-U_{h}(w \mid 1) \\
& =\frac{1-e^{-x_{\varnothing}}}{x_{\varnothing}}\left(\pi+(1-\pi) y^{m}\right) \beta-\pi e^{-x^{h}} .
\end{aligned}
$$

We start with showing that $\Phi(\beta)$ has a unique maximum at $\beta^{*}$ with $\Phi\left(\beta^{*}\right)>0$. The unique 
maximum follows from,

$$
\begin{aligned}
& \frac{\partial \Phi(\beta)}{\partial \beta}=\left(\frac{1-e^{-x_{\varnothing}}}{x_{\varnothing}}-\frac{1-e^{-x_{\varnothing}}-x_{\varnothing} e^{-x_{\varnothing}}}{\left(x_{\varnothing}\right)^{2}} \frac{d x_{\varnothing}}{d \beta} \beta\right)\left(\pi+(1-\pi) y^{m}\right) \\
& =\left(1-\frac{1-e^{-x_{\varnothing}}}{x_{\varnothing} e^{-x_{\varnothing}}} \beta\right) \frac{1}{1-\beta} \frac{1-e^{-x_{\varnothing}}}{x_{\varnothing}}\left(\pi+(1-\pi) y^{m}\right) \\
& \frac{\partial \Phi\left(\beta^{*}\right)}{\partial \beta^{*}}=0 \Longleftrightarrow \beta^{*}=\frac{x_{\varnothing} e^{-x_{\varnothing}}}{1-e^{-x_{\varnothing}}} \\
& \frac{\partial^{2} \Phi(\beta)}{\partial \beta \partial \beta}=-\left(1-\frac{1-e^{-x_{\varnothing}}}{x_{\varnothing}}\right) \frac{1}{x_{\varnothing} e^{-x_{\varnothing}}} \frac{d x_{\varnothing}}{d \beta} \frac{\beta}{1-\beta} \frac{1-e^{-x_{\varnothing}}}{x_{\varnothing}}\left(\pi+(1-\pi) y^{m}\right) \\
& -\frac{1-e^{-x \varnothing}}{x_{\varnothing} e^{-x_{\varnothing}}} \frac{1}{1-\beta} \frac{1-e^{-x \varnothing}}{x_{\varnothing}}\left(\pi+(1-\pi) y^{m}\right) \\
& +\left(1-\frac{1-e^{-x_{\varnothing}}}{x_{\varnothing} e^{-x_{\varnothing}}} \beta\right) \frac{1}{(1-\beta)^{2}} \frac{1-e^{-x_{\varnothing}}}{x_{\varnothing}}\left(\pi+(1-\pi) y^{m}\right) \\
& -\left(1-\frac{1-e^{-x_{\varnothing}}}{x_{\varnothing} e^{-x_{\varnothing}}} \beta\right) \frac{1}{1-\beta} \frac{1-e^{-x_{\varnothing}}-x_{\varnothing} e^{-x_{\varnothing}}}{\left(x_{\varnothing}\right)^{2}} \frac{d x_{\varnothing}}{d \beta}\left(\pi+(1-\pi) y^{m}\right) \\
& =-\left(1-\frac{1-e^{-x_{\varnothing}}}{x_{\varnothing}}\right) \frac{1}{x_{\varnothing} e^{-x_{\varnothing}}} \frac{d x_{\varnothing}}{d \beta} \frac{\beta}{1-\beta} \frac{1-e^{-x_{\varnothing}}}{x_{\varnothing}}\left(\pi+(1-\pi) y^{m}\right) \\
& -\left(\frac{1-e^{-x_{\varnothing}}}{x_{\varnothing} e^{-x_{\varnothing}}}-1\right) \frac{1}{(1-\beta)^{2}} \frac{1-e^{-x_{\varnothing}}}{x_{\varnothing}}\left(\pi+(1-\pi) y^{m}\right) \\
& -\left(1-\frac{1-e^{-x_{\varnothing}}}{x_{\varnothing} e^{-x_{\varnothing}}} \beta\right) \frac{1}{1-\beta} \frac{1-e^{-x_{\varnothing}}-x_{\varnothing} e^{-x_{\varnothing}}}{\left(x_{\varnothing}\right)^{2}} \frac{d x_{\varnothing}}{d \beta}\left(\pi+(1-\pi) y^{m}\right) \\
& <0 \text {. }
\end{aligned}
$$

where the vacancy creation condition for wage-bargaining firms gives,

$$
\begin{aligned}
\Pi\left(w_{\varnothing} \mid y^{m}\right) & =\left[m \pi+(1-\pi) y^{m}\right](1-\beta)\left(1-e^{-x_{\varnothing}}\right)=k \\
& \Longrightarrow \frac{d x_{\varnothing}}{d \beta}=\frac{1}{1-\beta} \frac{1-e^{-x_{\varnothing}}}{e^{-x_{\varnothing}}} .
\end{aligned}
$$

Let us now show that $\Phi\left(\beta^{*}\right)>0$ for $(1-m) / y^{m} \geq C^{*}$, where $C^{*}$ is implicitly defined by $D\left(C^{*}\right)=0$ in equation (22). Evaluating $\Phi(\beta)$ at $\beta^{*}$ implies,

$$
\Phi\left(\beta^{*}\right)=\left(\pi+(1-\pi) y^{m}\right) e^{-x \varnothing}-\pi e^{-x^{h}}
$$

Let us start with showing that $\Phi\left(\beta^{*} \mid C=C^{*}\right)>0$. To do so note first that the utility for high-type workers at wage-posting firms evaluated at $C^{*}$, i.e., $U_{h}(w \mid 1)=U_{h}\left(w \mid y^{m}\right)$, imply,

$$
\frac{m+\frac{1-\pi}{\pi} y^{m}}{m+\frac{1-\pi}{\pi}} e^{-x^{m}}=\pi e^{-x^{h}}
$$

The vacancy creation conditions for wage-posting firms in (10) evaluated at $C^{*}$ and the vacancy creation condition for wage-bargaining firms at $C^{*}$ and $\beta^{*}$ implies $x^{m}=x_{\varnothing}$, i.e.,

$$
\begin{aligned}
\Pi\left(w \mid y^{m}\right) & =\left.\Pi\left(w_{\varnothing} \mid y^{m}\right)\right|_{\beta=\beta^{*}}=k \\
{\left[m \pi+(1-\pi) y^{m}\right]\left(1-e^{-x^{m}}-x^{m} e^{-x^{m}}\right) } & =\left[m \pi+(1-\pi) y^{m}\right]\left(1-e^{-x_{\varnothing}}-x_{\varnothing} e^{-x_{\varnothing}}\right) .
\end{aligned}
$$


We therefore get,

$$
\begin{aligned}
\Phi\left(\beta^{*} \mid C=C^{*}\right) & =\left(\pi+(1-\pi) y^{m}\right) e^{-x \varnothing}-\pi \frac{m+\frac{1-\pi}{\pi} y^{m}}{m+\frac{1-\pi}{\pi}} e^{-x_{\varnothing}} \\
& =(1-\pi) \frac{\pi\left(1-y^{m}\right)+m \pi y^{m}+(1-\pi) y^{m}}{m \pi+(1-\pi)} e^{-x_{\varnothing}}>0 .
\end{aligned}
$$

Furthermore, note that at $C \rightarrow \infty$, we have $y^{m} \rightarrow 0$,

$$
\lim _{C \rightarrow \infty} \Phi\left(\beta^{*}\right)=\pi e^{-x \varnothing}-\pi e^{-x^{h}}<0
$$

since $x_{\varnothing}>x^{h}$ due to the vacancy creation conditions of wage-bargaining and wage-posting firms evaluated at $y^{m} \rightarrow 0$, i.e.,

$$
m \pi\left(1-e^{-x_{\varnothing}}-x_{\varnothing} e^{-x_{\varnothing}}\right)=\pi\left(1-e^{-x^{h}}-x^{h} e^{-x^{h}}\right) .
$$

Since $\Phi\left(\beta^{*} \mid C=C^{*}\right)>0$ and $\lim _{C \rightarrow \infty} \Phi\left(\beta^{*}\right)$ and since $\Phi\left(\beta^{*}\right)$ is continuous in $C$ (using the function $\left.m(C)=1-y^{m} C\right)$ it follows that a $C^{* *}$ exists such that $\left.\Phi\left(\beta^{*}\right)\right|_{C=C^{* *}}=0$. Uniqueness of $C^{* *}$ follows from

$$
\frac{\partial \Phi\left(\beta^{*}\right)}{\partial C}=\left(\pi+(1-\pi) y^{m}\right) e^{-x_{\varnothing}} \frac{d x_{\varnothing}}{d C}>0 .
$$

where we know that $d x_{\varnothing} / d C>0$ from using the implicit function theorem for the vacancy creation condition, i.e.,

$$
\begin{aligned}
k & =\left[m(C) \pi+(1-\pi) y^{m}\right]\left(1-e^{-x_{\varnothing}}-x_{\varnothing} e^{-x_{\varnothing}}\right), \\
& \Longrightarrow \frac{d x_{\varnothing}}{d C}=\frac{y^{m}\left(1-e^{-x_{\varnothing}}-x_{\varnothing} e^{-x_{\varnothing}}\right)}{\left[m(C) \pi+(1-\pi) y^{m}\right] x_{\varnothing} e^{-x_{\varnothing}}}>0 .
\end{aligned}
$$

We can summarize that there exists a unique $C^{* *} \in\left(C^{*}, \infty\right)$ such that $\left.\Phi\left(\beta^{*}\right)\right|_{C=C^{* *}}=0$. Thus for $C>C^{* *}$ no pure wage-bargaining equilibrium exists. For $C \in\left[C^{*}, C^{* *}\right]$ a pure wage-bargaining equilibrium exists. It follows that for $C \in\left[C^{*}, C^{* *}\right]$ there exist $\underline{b}<\beta^{*}<\bar{b}$ such that $\Phi(\underline{b})=0$ and $\Phi(\bar{b})=0$. Note, that $0<\underline{b}$ and $\bar{b}<1$, since $\lim _{\beta \rightarrow 0} \Phi(\beta)<0$ and $\lim _{\beta \rightarrow 1} \Phi(\beta)<0$.

Let us in a second step focus on the range $C \in\left[C^{*}, C^{* *}\right]$ and show that for $\beta \in(\underline{p}, \underline{b}) \cup(\bar{b}, \bar{p})$ a coexistence equilibrium with wage-posting and wage-bargaining and hiring thresholds $\bar{y}=1$ and $\bar{y}_{\varnothing}=y^{m}$ exists. At $\beta=\underline{b}$ and $\beta=\bar{b}$ we know that $\Phi(\underline{b})=0$ and $\Phi(\bar{b})=0$ such that all high-type workers apply at wage-bargaining firms, i.e., $\gamma^{h}=0$. In the following we prove that for $\beta \in(\underline{p}, \underline{b}) \cup(\bar{b}, \bar{p})$ there exists a $\gamma^{h} \in(0,1)$ such that high-type workers are indifferent between wage-posting and wage-bargaining, i.e.,

$$
\Psi\left(\beta, \gamma^{h}\right)=U_{h}\left(w_{\varnothing} \mid y^{m}\right)-U_{h}(w \mid 1)=\frac{1-e^{-x_{\varnothing}}}{x_{\varnothing}}\left(\pi+(1-\pi) y^{m}\right) \beta-\pi e^{-x^{h}}=0,
$$

and the vacancy creation conditions for wage-bargaining and wage-posting firms hold. We will now show that a $\Psi\left(\beta, \gamma^{h}\right)=0$ exists for $\gamma^{h} \in(0,1)$ and $\beta \in(\underline{p}, \underline{b}) \cup(\bar{b}, \bar{p})$. Note first that the fact that wage-bargaining firms are the only firms to hire workers with a medium match quality implies that all low-type workers apply at the wage-bargaining, i.e., $\gamma^{l}=0$. The vacancy creation condition for wage-bargaining firms implies,

$$
\Pi\left(w_{\varnothing} \mid y^{m}\right)=\left(1-e^{-x_{\varnothing}}\right)(1-\beta) \frac{m\left(1-\gamma^{h}\right)\left(\pi+(1-\pi) y^{m}\right)+(1-m)(1-\pi) y^{m}}{m\left(1-\gamma^{h}\right)+(1-m)}=k .
$$


For later reference we note that,

$$
\begin{aligned}
\frac{d x_{\varnothing}}{d \gamma^{h}} & =\frac{m\left(\pi+(1-\pi) y^{m}\right)}{m\left(1-\gamma^{h}\right)\left(\pi+(1-\pi) y^{m}\right)+(1-m)(1-\pi) y^{m}} \frac{1-e^{-x_{\varnothing}}}{e^{-x_{\varnothing}}}>0, \\
\frac{d x_{\varnothing}}{d \beta} & =\frac{1}{1-\beta} \frac{1-e^{-x_{\varnothing}}}{e^{-x_{\varnothing}}}>0 .
\end{aligned}
$$

Using the Implicit Function Theorem for $\Psi\left(\beta, \gamma^{h}\right)=0$ we can show that $\widetilde{\gamma}^{h}(\beta)$ is a continuous and strictly increasing function on $(0, \underline{b}]$ and a continuous and strictly decreasing function on $[\bar{b}, 1)$. That is,

$$
\begin{aligned}
\frac{\partial \Psi\left(\beta, \gamma^{h}\right)}{\partial \gamma^{h}}= & -\frac{1-e^{-x_{\varnothing}}-x_{\varnothing} e^{-x_{\varnothing}}}{\left(x_{\varnothing}\right)^{2}} \frac{d x_{\varnothing}}{d \gamma^{h}}\left(\pi+(1-\pi) y^{m}\right) \beta<0 \\
\frac{\partial \Psi\left(\beta, \gamma^{h}\right)}{\partial \beta}= & -\frac{1-e^{-x_{\varnothing}}-x_{\varnothing} e^{-x_{\varnothing}}}{\left(x_{\varnothing}\right)^{2}} \frac{d x_{\varnothing}}{d \beta}\left(\pi+(1-\pi) y^{m}\right) \beta \\
& +\frac{1-e^{-x_{\varnothing}}}{x_{\varnothing}}\left(\pi+(1-\pi) y^{m}\right) \\
= & \left(1-\frac{1-e^{-x_{\varnothing}}-x_{\varnothing} e^{-x_{\varnothing}}}{x_{\varnothing} e^{-x_{\varnothing}}} \frac{\beta}{1-\beta}\right) \frac{1-e^{-x_{\varnothing}}}{x_{\varnothing}}\left(\pi+(1-\pi) y^{m}\right)
\end{aligned}
$$

implies

$$
\begin{aligned}
& \frac{d \gamma^{h}}{d \beta}=-\frac{\partial \Psi\left(\beta, \gamma^{h}\right) / \partial \beta}{\partial \Psi\left(\beta, \gamma^{h}\right) / \partial \gamma^{h}}>0 \text { for } \beta<\beta^{*}=\frac{x_{\varnothing} e^{-x_{\varnothing}}}{1-e^{-x_{\varnothing}}}, \\
& \frac{d \gamma^{h}}{d \beta}=-\frac{\partial \Psi\left(\beta, \gamma^{h}\right) / \partial \beta}{\partial \Psi\left(\beta, \gamma^{h}\right) / \partial \gamma^{h}}<0 \text { for } \beta>\beta^{*}=\frac{x_{\varnothing} e^{-x_{\varnothing}}}{1-e^{-x_{\varnothing}}}
\end{aligned}
$$

with $\widetilde{\gamma}^{h}(\underline{b})=\widetilde{\gamma}^{h}(\bar{b})=0$ according to the definition of $\underline{b}$ and $\bar{b}$. Continuity implies that there exists a lower bound $\underline{p} \in(0, \underline{b})$ such that $\Psi\left(\underline{p}, \widetilde{\gamma}^{h}(\underline{p})\right)=0$ and an upper bound $\bar{p} \in(\bar{b}, 1)$ such that $\Psi\left(\bar{p}, \widetilde{\gamma}^{h}(\bar{p})\right)=0$, since $\lim _{\beta \rightarrow 0} \Psi\left(\beta, \widetilde{\gamma}^{h}(\beta)\right)<0$ and $\lim _{\beta \rightarrow 1} \Psi\left(\beta, \widetilde{\gamma}^{h}(\beta)\right)<0$. Note that $\widetilde{\gamma}^{h}(\underline{p}) \in(0,1)$ and $\widetilde{\gamma}^{h}(\bar{p}) \in(0,1)$, since $\lim _{\gamma^{h} \rightarrow 0} \Psi\left(\beta, \gamma^{h}\right)<0$.

In the third step we focus again on the range $C \in\left[C^{*}, C^{* *}\right]$ and show that for $\beta \in$ $(0, \underline{p}] \cup[\bar{p}, 1)$ a pure wage-posting equilibrium with hiring thresholds $\bar{y}=1$ exists. The existence of a pure-wage posting equilibrium for $\beta \in(0, p] \cup[\bar{p}, 1)$ follows from the fact that $\widetilde{\gamma}^{h}(\beta)$ is a continuous and strictly increasing function on $(0, \underline{p}] \subset(0, \underline{b})$ and a continuous and strictly decreasing function on $[\bar{p}, 1) \subset(\bar{b}, 1)$. To see this note that by the definition of of $p$ and $\bar{p}$ the utility of a high-type worker from applying at a wage-bargaining firm with hiring thresholds $\bar{y}_{\varnothing}=y^{m}$ equals the utility from applying at a wage-posting firm with hiring thresholds $\bar{y}=1$, i.e., $\Psi\left(\underline{p}, \widetilde{\gamma}^{h}(\underline{p})\right)=0$ and $\Psi\left(\bar{p}, \widetilde{\gamma}^{h}(\bar{p})\right)=0$. Thus, $\Psi\left(\beta, \widetilde{\gamma}^{h}(\beta)\right)<0$ for any $\beta \in(0, p)$ and $\beta \in(\bar{p}, 1)$, i.e., the utility of a high-type worker from applying at a wagebargaining firm with hiring thresholds $\bar{y}_{\varnothing}=y^{m}$ falls below the utility from applying at a wage-posting firm with hiring thresholds $\bar{y}=1$.

Finally, we show that for $C>C^{* *}$ only a pure-wage-posting equilibrium with hiring thresholds $\bar{y}=1$ exists. We have already shown above that a pure wage-bargaining equilibrium cannot exist. We prove that by contradiction a coexistence equilibrium cannot exist either. Suppose a coexistence equilibrium exist. Then it must be true that $\Psi\left(\beta^{*}, \gamma^{h}\right) \geq \Phi\left(\beta^{*}\right)$ for $\gamma^{h} \in(0,1)$. But equation (23), i.e., $\partial \Psi\left(\beta, \gamma^{h}\right) / \partial \gamma^{h}<0$, implies that $\Psi\left(\beta, \gamma^{h}\right)$ is maximized at $\gamma^{h}=0$. Since $\Psi\left(\beta^{*}, 0\right)=\Phi\left(\beta^{*}\right)$ by construction, we have the desired contradiction. $Q E D$ 


\section{A.4 Proof of Theorem 2}

To simplify the notation we define $x_{\varnothing} \equiv x\left(w_{\varnothing} \mid y^{m}\right), x^{m} \equiv x\left(w \mid y^{m}\right)$ and $x^{h} \equiv x(w \mid 1)$. Lemma 3 implies that wage-posting firms choose the hiring threshold $\bar{y}=y^{m}$ in the range $(1-m) / y^{m}<C^{*}$. First note that the Hosios condition implies that the deviation of a wage-bargaining firm to a hiring threshold $\bar{y}_{\varnothing}=1$ is always dominated by a deviation to wage-posting with $\bar{y}=1$, which again is dominated by $\bar{y}=y^{m}$ for $(1-m) / y^{m}<C^{*}$ as stated by Lemma 3 . We therefore only need to consider wage-posting firms with the hiring threshold $\bar{y}=y^{m}$ and wage-bargaining firms with the hiring threshold $\bar{y}_{\varnothing}=y^{m}$.

Lemmas 1 to 3 imply that in the range $(1-m) / y^{m}<C^{*}$ wage-posting firms - irrespective of whether they are equilibrium firms or deviating firms - can offer high-type workers the following utility

$$
U_{h}\left(w \mid y^{m}\right)=\frac{m \pi+(1-\pi) y^{m}}{m \pi+(1-\pi)} e^{-x^{m}}
$$

where $x^{m}$ is given by the vacancy creation condition,

$$
\Pi\left(w \mid y^{m}\right)=\left[m \pi+(1-\pi) y^{m}\right]\left(1-e^{-x^{m}}-x^{m} e^{-x^{m}}\right)=k,
$$

where the assumption that $k$ is sufficiently small to ensure existence implies $k<m \pi+$ $(1-\pi) y^{m}$. Note that the utility level for high-type workers $U_{h}\left(w \mid y^{m}\right)$ is independent of workers bargaining power parameter $\beta$.

In case of the wage-bargaining firm we have to differentiate whether the wage-bargaining firm is in equilibrium or deviating. Let us start with characterizing the pure wage-bargaining equilibrium. Since by the definition of the pure wage-bargaining equilibrium only wagebargaining firms exist, all high- and low-type workers will apply at wage-bargaining firms, i.e., $\gamma^{h}=\gamma^{l}=0$. This gives the following equilibrium utility for high-type workers,

$$
U_{h}\left(w_{\varnothing} \mid y^{m}\right)=\frac{1-e^{-x \varnothing}}{x_{\varnothing}}\left(\pi+(1-\pi) y^{m}\right) \beta,
$$

where the equilibrium vacancy creation condition determines $x_{\varnothing}$, i.e.,

$$
\Pi\left(w_{\varnothing} \mid y^{m}\right)=\left(1-e^{-x_{\varnothing}}\right)\left[m \pi+(1-\pi) y^{m}\right](1-\beta)=k .
$$

Let us now define

$$
\begin{aligned}
\Lambda(\beta) & =U_{h}\left(w_{\varnothing} \mid y^{m}\right)-U_{h}\left(w \mid y^{m}\right) \\
& =\frac{1-e^{-x_{\varnothing}}}{x_{\varnothing}}\left(\pi+(1-\pi) y^{m}\right) \beta-\frac{m \pi+(1-\pi) y^{m}}{m \pi+(1-\pi)} e^{-x^{m}} .
\end{aligned}
$$

Note that $\Lambda(\beta)$ has the same properties as $\Phi(\beta)$ in section A.3 in the Appendix, since $U_{h}\left(w \mid y^{m}\right)$ is independent of $\beta$. This implies that $\Lambda(\beta)$ has a unique maximum at $\beta^{*}=$ $x_{\varnothing} e^{-x_{\varnothing}} / 1-e^{-x_{\varnothing}}$. Evaluating the vacancy creation condition for wage-bargaining firms at $\beta^{*}$ and substituting $k$ using the vacancy creation condition of a deviating wage-posting firm as stated in equation (24) implies $x_{\varnothing}=x^{m}$. Evaluating $\Lambda(\beta)$ at $\beta^{*}$ implies,

$$
\begin{aligned}
\Lambda\left(\beta^{*}\right) & =\left(\pi+(1-\pi) y^{m}\right) e^{-x \varnothing}-\frac{m \pi+(1-\pi) y^{m}}{m \pi+(1-\pi)} e^{-x^{m}} \\
& =(1-\pi) \frac{\pi\left(1-y^{m}\right)+m \pi y^{m}+(1-\pi) y^{m}}{m \pi+(1-\pi)} e^{-x_{\varnothing}}>0 .
\end{aligned}
$$


Hence for $(1-m) / y^{m}<C^{*}$ a pure wage-bargaining exists in the range $\underline{b}^{\prime}<\beta^{*}<\bar{b}^{\prime}$, where $\Lambda\left(\underline{b}^{\prime}\right)=0$ and $\Lambda\left(\bar{b}^{\prime}\right)=0$. Note, that $0<\underline{b}^{\prime}$ and $\bar{b}^{\prime}<1$, since $\lim _{\beta \rightarrow 0} \Lambda(\beta)<0$ and $\lim _{\beta \rightarrow 1} \Lambda(\beta)<0$.

Next, we consider a pure wage-posting equilibrium with $U_{h}\left(w \mid y^{m}\right)$ given above and vacancy creation condition in equation (24). A deviating wage-bargaining firm can set a hiring threshold $\bar{y}_{\varnothing}=y^{m}$ and still attract only high-type workers, since wage-posting firms will according to Lemma 1 attract all low-type workers. The deviation utility that a wage-bargaining firm can offer to suitable worker is hence equal to

$$
U_{h}^{d}\left(w_{\varnothing} \mid y^{m}\right)=\frac{1-e^{-x_{\varnothing}^{d}}}{x_{\varnothing}^{d}}\left(\pi+(1-\pi) y^{m}\right) \beta,
$$

where $x_{\varnothing}^{d}$ is determined by the respective vacancy creation condition, i.e.,

$$
\Pi^{d}\left(w_{\varnothing} \mid y^{m}\right)=\left(1-e^{-x_{\varnothing}^{d}}\right)\left(\pi+(1-\pi) y^{m}\right)(1-\beta)=k .
$$

Let us now define

$$
\begin{aligned}
\Theta(\beta) & =U_{h}\left(w \mid y^{m}\right)-U_{h}^{d}\left(w_{\varnothing} \mid y^{m}\right) \\
& =\frac{m \pi+(1-\pi) y^{m}}{m \pi+(1-\pi)} e^{-x^{m}}-\frac{1-e^{-x_{\varnothing}^{d}}}{x_{\varnothing}^{d}}\left(\pi+(1-\pi) y^{m}\right) \beta .
\end{aligned}
$$

Note that $\Theta(\beta)$ has a unique minimum at $\beta^{*}$, since $\Theta(\beta)$ has the same properties as $\Phi(\beta)$ in section A.3 in the Appendix except that $U_{h}^{d}\left(w_{\varnothing} \mid y^{m}\right)$ enters $\Theta(\beta)$ with a minus sign while $U_{h}\left(w_{\varnothing} \mid y^{m}\right)$ enters $\Phi(\beta)$ with a plus sign. Evaluating the deviating vacancy creation condition for wage-bargaining firms in equation (25) at $\beta^{*}$ and substituting $k$ using the vacancy creation condition of the wage-posting firm in equation (24) implies $x_{\varnothing}^{d}<x^{m}$ since,

$$
1-e^{-x_{\varnothing}^{d}}-x_{\varnothing}^{d} e^{-x_{\varnothing}^{d}}=\frac{m \pi+(1-\pi) y^{m}}{\pi+(1-\pi) y^{m}}\left(1-e^{-x^{m}}-x^{m} e^{-x^{m}}\right) .
$$

Evaluating $\Theta(\beta)$ at $\beta^{*}$ implies

$$
\Theta\left(\beta^{*}\right)=\frac{m \pi+(1-\pi) y^{m}}{m \pi+(1-\pi)} e^{-x^{m}}-\left(\pi+(1-\pi) y^{m}\right) e^{-x_{\varnothing}^{d}}<0
$$

since $x_{\varnothing}^{d}<x^{m}$ and

$$
\frac{m \pi+(1-\pi) y^{m}}{m \pi+(1-\pi)}-\left(\pi+(1-\pi) y^{m}\right)<0
$$

We have therefore shown that $\Theta(\beta)$ has a unique minimum at $\beta^{*}$ with $\Theta\left(\beta^{*}\right)<0$ for $(1-m) / y^{m}<C^{*}$. It follows that there exist $0<\underline{p}^{\prime}<\beta^{*}<\bar{p}^{\prime}<1$ such that $\Theta\left(\underline{p}^{\prime}\right)=0$ and $\Theta\left(\bar{p}^{\prime}\right)=0$, since $\lim _{\beta \rightarrow 0} \Theta(\beta)>0$ and $\lim _{\beta \rightarrow 1} \Theta(\bar{\beta})>0$.

In the next step we show that $\underline{p}^{\prime}<\underline{b}^{\prime}$ and $\bar{b}^{\prime}<\bar{p}^{\prime}$ and that no equilibrium exists for $\beta \in\left[\underline{p}^{\prime}, \underline{b}^{\prime}\right) \cup\left(\bar{b}^{\prime}, \bar{p}^{\prime}\right]$. The proof is by contradiction. Suppose $\underline{p}^{\prime} \geq \underline{b}^{\prime}\left(\bar{b}^{\prime} \geq \bar{p}^{\prime}\right)$, which implies that a pure wage-posting and a pure wage-bargaining equilibrium can exist in the same parameter range. Since $U_{h}\left(w \mid y^{m}\right)$ is independent of $\beta, \underline{p}^{\prime} \geq \underline{b}^{\prime}\left(\bar{b}^{\prime} \geq \bar{p}^{\prime}\right)$ implies that $\Lambda\left(\underline{p}^{\prime}\right)>0\left(\Lambda\left(\bar{p}^{\prime}\right)>0\right)$. The respective vacancy creation conditions, evaluated at $\underline{p}^{\prime}$, can be used to substitute out $k$, i.e.,

$$
\left[m \pi+(1-\pi) y^{m}\right]\left(1-\underline{p}^{\prime}\right)\left(1-e^{-x_{\varnothing}}\right)=\left[\pi+(1-\pi) y^{m}\right]\left(1-\underline{p}^{\prime}\right)\left(1-e^{-x_{\varnothing}^{d}}\right) .
$$


This implies $x_{\varnothing}>x_{\varnothing}^{d}$. Substituting $U_{h}\left(w \mid y^{m}\right)$ in $\Lambda\left(\underline{p}^{\prime}\right)$ using $\Theta\left(\underline{p}^{\prime}\right)=0$ implies the desired contradiction,

$$
\Lambda\left(\underline{p}^{\prime}\right)=\frac{1-e^{-x_{\varnothing}}}{x_{\varnothing}}\left(\pi+(1-\pi) y^{m}\right) \underline{p}^{\prime}-\frac{1-e^{-x_{\varnothing}^{d}}}{x_{\varnothing}^{d}}\left(\pi+(1-\pi) y^{m}\right) \underline{p}^{\prime}<0,
$$

since $x_{\varnothing}>x_{\varnothing}^{d}$. The same argument can be made for $\Lambda\left(\bar{p}^{\prime}\right)$. Thus, neither a pure wageposting nor a pure wage-bargaining equilibrium exists for $\beta \in\left[\underline{p}^{\prime}, \underline{b}^{\prime}\right) \cup\left(\bar{b}^{\prime}, \bar{p}^{\prime}\right]$. A coexistence with both wage-posting and wage-bargaining firms cannot be optimal either, since Lemma 2 implies that wage-posting firms will always deviate to offer a wage that attracts all high-type workers, i.e., $\gamma^{h}=1$. But $\gamma^{h} \in(0,1)$ is essential to have positive profits for both wage-posting and wage-bargaining firms. $Q E D$ 


\section{B Appendix: Data Description and Regression Results}

Table B.1: Descriptive statistics of regression sample

\begin{tabular}{|c|c|c|}
\hline Variable & Mean & Std. Dev. \\
\hline $\log$ (applicants) & 2.1378 & 1.0723 \\
\hline Share of suitable applicants* & 0.4982 & 0.3270 \\
\hline Bargaining & 0.3093 & 0.4622 \\
\hline \multicolumn{3}{|l|}{ Plant size } \\
\hline$<20$ employees & 0.2458 & 0.4306 \\
\hline 20 - 49 employees & 0.3030 & 0.4596 \\
\hline 50 - 199 employees & 0.2827 & 0.4503 \\
\hline 200 - 499 employees & 0.1001 & 0.3002 \\
\hline $500+$ employees & 0.0684 & 0.2524 \\
\hline Low sales & 0.1053 & 0.3070 \\
\hline Skilled labor shortage & 0.1048 & 0.3063 \\
\hline Share of highly qualified employees & 0.1832 & 0.2210 \\
\hline Share of female employees & 0.4784 & 0.2832 \\
\hline Share of part-time employees & 0.2427 & 0.2522 \\
\hline Share of temporary employees & 0.1059 & 0.1601 \\
\hline Newly created job & 0.8483 & 0.3588 \\
\hline \multicolumn{3}{|l|}{ Required qualification } \\
\hline Unqualified & 0.0916 & 0.2885 \\
\hline Intermediate qualification & 0.7047 & 0.4562 \\
\hline Higher qualification & 0.2037 & 0.4028 \\
\hline Long-term experience in occupational field & 0.4605 & 0.4985 \\
\hline Managerial skills & 0.1045 & 0.3059 \\
\hline Part-time job & 0.1298 & 0.3361 \\
\hline Regional unemployment rate & 0.0789 & 0.0337 \\
\hline \multicolumn{3}{|l|}{ Classification of Economic Activities } \\
\hline Agriculture, forestry and fishing & 0.0185 & 0.1348 \\
\hline Mining and quarrying & 0.0120 & 0.1089 \\
\hline Food; textile, clothes and furniture & 0.0335 & 0.1799 \\
\hline Wood, paper and printing & 0.0277 & 0.1641 \\
\hline Coke and refined petroleum products, chemicals and plastic products & 0.0356 & 0.1852 \\
\hline Basic metals, fabricated metal products & 0.0360 & 0.1864 \\
\hline Machinery and equipment, electrical equipment and motor vehicles & 0.0411 & 0.1985 \\
\hline Electricity, gas, steam and air conditioning supply & 0.0330 & 0.1787 \\
\hline Water supply; sewerage, waste management and remediation activities & 0.0350 & 0.1838 \\
\hline Construction & 0.0246 & 0.1548 \\
\hline Wholesale and retail trade; repair of motor vehicles and motorcycles & 0.0356 & 0.1852 \\
\hline Transportation and storage & 0.0348 & 0.1834 \\
\hline Accommodation and food service activities & 0.0398 & 0.1955 \\
\hline Information and communication & 0.0356 & 0.1852 \\
\hline Financial and insurance activities & 0.0362 & 0.1868 \\
\hline Real estate activities & 0.0370 & 0.1889 \\
\hline Professional, scientific and technical activities & 0.0392 & 0.1942 \\
\hline Administrative and support service activities & 0.0368 & 0.1882 \\
\hline Public administration and defense; compulsory social security & 0.1172 & 0.3216 \\
\hline Education & 0.0936 & 0.2913 \\
\hline Human health and social work activities & 0.0910 & 0.2876 \\
\hline Arts, entertainment and recreation & 0.0313 & 0.1740 \\
\hline Other service activities & 0.0750 & 0.2634 \\
\hline Continued next sid & & \\
\hline
\end{tabular}


Table B.1: Descriptive statistics of regression sample

\begin{tabular}{lcr}
\hline Variable & Mean & Std. Dev. \\
\hline 2011 & 0.3574 & 0.4793 \\
2012 & 0.3036 & 0.4598 \\
2013 & 0.3390 & 0.4734 \\
\hline
\end{tabular}

Source: German Job Vacancy Survey 2011-2013. 15.166 observations (*: 14811 observations); regional unemployment rates are for 409 administrative districts (Landkreise und kreisfreie Stdte NUTS3 regions); 'unqualified' means without occupational training; 'higher qualification' indicates college or university degree. 
Table B.2: Regression on number of applicants I

\begin{tabular}{|c|c|c|c|c|}
\hline & $\begin{array}{l}1 \\
\text { OLS }\end{array}$ & $\begin{array}{c}2 \\
\text { ZTNB }\end{array}$ & $\begin{array}{l}3 \\
\text { OLS }\end{array}$ & $\begin{array}{c}4 \\
\text { ZTNB }\end{array}$ \\
\hline Bargaining & $\begin{array}{c}0.0118 \\
(0.5174)\end{array}$ & $\begin{array}{c}0.0141 \\
(0.7102)\end{array}$ & $\begin{array}{c}-0.0118 \\
(0.5939)\end{array}$ & $\begin{array}{c}0.0125 \\
(0.7781)\end{array}$ \\
\hline Plant size: $20-49$ & $\begin{array}{c}0.0562 \\
(0.0073)\end{array}$ & $\begin{array}{c}0.0686 \\
(0.1235)\end{array}$ & $\begin{array}{c}0.0550 \\
(0.0298)\end{array}$ & $\begin{array}{c}0.0483 \\
(0.3556)\end{array}$ \\
\hline $50-199$ & $\begin{array}{c}0.2379 \\
(0.0000)\end{array}$ & $\begin{array}{c}0.3701 \\
(0.0000)\end{array}$ & $\begin{array}{c}0.2468 \\
(0.0000)\end{array}$ & $\begin{array}{c}0.3622 \\
(0.0000)\end{array}$ \\
\hline $200-499$ & $\begin{array}{c}0.5277 \\
(0.0000)\end{array}$ & $\begin{array}{c}0.6946 \\
(0.0000)\end{array}$ & $\begin{array}{c}0.5232 \\
(0.0000)\end{array}$ & $\begin{array}{c}0.6939 \\
(0.0000)\end{array}$ \\
\hline $500+$ & $\begin{array}{c}0.7056 \\
(0.0000)\end{array}$ & $\begin{array}{c}1.1137 \\
(0.0000)\end{array}$ & $\begin{array}{c}0.7244 \\
(0.0000)\end{array}$ & $\begin{array}{c}1.1352 \\
(0.0000)\end{array}$ \\
\hline Low sales & $\begin{array}{c}-0.0901 \\
(0.0001)\end{array}$ & $\begin{array}{c}-0.2198 \\
(0.0000)\end{array}$ & $\begin{array}{c}-0.0776 \\
(0.0083)\end{array}$ & $\begin{array}{r}-0.1763 \\
(0.0038)\end{array}$ \\
\hline Skilled labor shortage & $\begin{array}{r}-0.0785 \\
(0.0005)\end{array}$ & $\begin{array}{r}-0.1493 \\
(0.0015)\end{array}$ & $\begin{array}{c}-0.1281 \\
(0.0000)\end{array}$ & $\begin{array}{r}-0.2395 \\
(0.0000)\end{array}$ \\
\hline Share of highly qualified employees & $\begin{array}{c}0.4956 \\
(0.0000)\end{array}$ & $\begin{array}{c}1.0227 \\
(0.0000)\end{array}$ & $\begin{array}{c}0.4870 \\
(0.0000)\end{array}$ & $\begin{array}{c}1.0872 \\
(0.0000)\end{array}$ \\
\hline Share of female employees & $\begin{array}{c}0.1959 \\
(0.0000)\end{array}$ & $\begin{array}{c}0.2789 \\
(0.0012)\end{array}$ & $\begin{array}{c}0.1917 \\
(0.0002)\end{array}$ & $\begin{array}{c}0.3042 \\
(0.0025)\end{array}$ \\
\hline Share of part-time employees & $\begin{array}{r}-0.1868 \\
(0.0000)\end{array}$ & $\begin{array}{r}-0.2841 \\
(0.0009)\end{array}$ & $\begin{array}{c}-0.1721 \\
(0.0006)\end{array}$ & $\begin{array}{r}-0.2609 \\
(0.0102)\end{array}$ \\
\hline Share of temporary employees & $\begin{array}{c}0.1910 \\
(0.0005)\end{array}$ & $\begin{array}{c}0.3376 \\
(0.0076)\end{array}$ & $\begin{array}{c}0.1741 \\
(0.0091)\end{array}$ & $\begin{array}{c}0.3535 \\
(0.0215)\end{array}$ \\
\hline Newly created job & $\begin{array}{c}0.1767 \\
(0.0000)\end{array}$ & $\begin{array}{c}0.2628 \\
(0.0000)\end{array}$ & $\begin{array}{c}0.1774 \\
(0.0000)\end{array}$ & $\begin{array}{c}0.2621 \\
(0.0000)\end{array}$ \\
\hline Required qualifikation: Unqualified & $\begin{array}{r}-0.1833 \\
(0.0000)\end{array}$ & $\begin{array}{r}-0.3047 \\
(0.0000)\end{array}$ & $\begin{array}{r}-0.2318 \\
(0.0000)\end{array}$ & $\begin{array}{r}-0.4269 \\
(0.0000)\end{array}$ \\
\hline Required qualifikation: High & $\begin{array}{c}0.0680 \\
(0.0081)\end{array}$ & $\begin{array}{c}0.0286 \\
(0.5296)\end{array}$ & $\begin{array}{c}0.0435 \\
(0.1547)\end{array}$ & $\begin{array}{r}-0.0228 \\
(0.6625)\end{array}$ \\
\hline Long-term experience & $\begin{array}{c}0.1026 \\
(0.0000)\end{array}$ & $\begin{array}{c}0.1014 \\
(0.0023)\end{array}$ & $\begin{array}{c}0.1000 \\
(0.0000)\end{array}$ & $\begin{array}{c}0.0765 \\
(0.0502)\end{array}$ \\
\hline Managerial skills & $\begin{array}{r}-0.0227 \\
(0.4112)\end{array}$ & $\begin{array}{c}-0.0611 \\
(0.2496)\end{array}$ & $\begin{array}{r}-0.0315 \\
(0.3330)\end{array}$ & $\begin{array}{c}-0.0901 \\
(0.1122)\end{array}$ \\
\hline Part-time job & $\begin{array}{r}-0.0171 \\
(0.5318)\end{array}$ & $\begin{array}{c}0.0363 \\
(0.4653)\end{array}$ & $\begin{array}{r}-0.0031 \\
(0.9218)\end{array}$ & $\begin{array}{c}0.0600 \\
(0.3030)\end{array}$ \\
\hline Regional unemployment rate & $\begin{array}{r}-0.5352 \\
(0.0273)\end{array}$ & $\begin{array}{c}0.3688 \\
(0.4546)\end{array}$ & $\begin{array}{c}-0.7206 \\
(0.0123)\end{array}$ & $\begin{array}{c}0.1977 \\
(0.7218)\end{array}$ \\
\hline Mining and quarrying & $\begin{array}{c}0.1855 \\
(0.0280)\end{array}$ & $\begin{array}{c}0.2548 \\
(0.2119)\end{array}$ & $\begin{array}{c}0.1984 \\
(0.0563)\end{array}$ & $\begin{array}{c}0.2642 \\
(0.3042)\end{array}$ \\
\hline Food; textile, clothes and furniture & $\begin{array}{c}0.1197 \\
(0.0724)\end{array}$ & $\begin{array}{c}0.2175 \\
(0.1515)\end{array}$ & $\begin{array}{c}0.1195 \\
(0.1462)\end{array}$ & $\begin{array}{c}0.1558 \\
(0.4346)\end{array}$ \\
\hline Wood, paper and printing & $\begin{array}{c}0.3254 \\
(0.0000)\end{array}$ & $\begin{array}{c}0.3669 \\
(0.0082)\end{array}$ & $\begin{array}{c}0.3680 \\
(0.0000)\end{array}$ & $\begin{array}{c}0.3320 \\
(0.0617)\end{array}$ \\
\hline $\begin{array}{l}\text { Coke, refined petroleum, } \\
\text { chemicals and plastic products }\end{array}$ & $\begin{array}{c}0.3432 \\
(0.0000)\end{array}$ & $\begin{array}{c}0.4808 \\
(0.0007)\end{array}$ & $\begin{array}{c}0.3379 \\
(0.0000)\end{array}$ & $\begin{array}{c}0.4601 \\
(0.0145)\end{array}$ \\
\hline $\begin{array}{l}\text { Basic metals, fabricated } \\
\text { metal products }\end{array}$ & $\begin{array}{c}0.2306 \\
(0.0004)\end{array}$ & $\begin{array}{c}0.3226 \\
(0.0221)\end{array}$ & $\begin{array}{c}0.2600 \\
(0.0013)\end{array}$ & $\begin{array}{c}0.2488 \\
(0.1631)\end{array}$ \\
\hline $\begin{array}{l}\text { Machinery and equipment, electrical } \\
\text { equipment and motor vehicles }\end{array}$ & $\begin{array}{c}0.2190 \\
(0.0007)\end{array}$ & $\begin{array}{c}0.3139 \\
(0.0302)\end{array}$ & $\begin{array}{c}0.1601 \\
(0.0435)\end{array}$ & $\begin{array}{c}0.0513 \\
(0.7706)\end{array}$ \\
\hline $\begin{array}{l}\text { Electricity, gas, steam and } \\
\text { air conditioning supply }\end{array}$ & $\begin{array}{c}0.7408 \\
(0.0000)\end{array}$ & $\begin{array}{l}1.1142 \\
(0.0000)\end{array}$ & $\begin{array}{c}0.7463 \\
(0.0000)\end{array}$ & $\begin{array}{l}1.0904 \\
(0.0000)\end{array}$ \\
\hline
\end{tabular}


Table B.2: Regression on number of applicants I

\begin{tabular}{lcccc}
\hline & 1 & 2 & 3 & 4 \\
& OLS & ZTNB & OLS & ZTNB \\
\hline Water supply; sewerage, waste & 0.5305 & 0.7626 & 0.5657 & 0.7704 \\
management and remediation & $(0.0000)$ & $(0.0000)$ & $(0.0000)$ & $(0.0000)$ \\
activities Construction & -0.1084 & -0.2453 & -0.1188 & -0.3934 \\
& $(0.1024)$ & $(0.1189)$ & $(0.1518)$ & $(0.0446)$ \\
Wholesale and retail trade; repair of & 0.3516 & 0.4839 & 0.2903 & 0.2582 \\
motor vehicles and motorcycles & $(0.0000)$ & $(0.0005)$ & $(0.0004)$ & $(0.1394)$ \\
\hline Transportation and storage & 0.2892 & 0.3744 & 0.3371 & 0.4033 \\
& $(0.0000)$ & $(0.0084)$ & $(0.0000)$ & $(0.0285)$ \\
Accommodation and food service & 0.1235 & 0.0639 & 0.1453 & 0.0180 \\
activities & $(0.0463)$ & $(0.6717)$ & $(0.0585)$ & $(0.9281)$ \\
Information and communication & 0.3297 & 0.5295 & 0.3798 & 0.4130 \\
& $(0.0000)$ & $(0.0010)$ & $(0.0000)$ & $(0.0232)$ \\
Financial and insurance activities & 0.2019 & 0.3711 & 0.1608 & 0.2681 \\
& $(0.0044)$ & $(0.0123)$ & $(0.0600)$ & $(0.1606)$ \\
Real estate activities & 0.7873 & 1.1770 & 0.8069 & 1.1809 \\
& $(0.0000)$ & $(0.0000)$ & $(0.0000)$ & $(0.0000)$ \\
\hline Professional, scientific and & 0.2229 & 0.3049 & 0.2591 & 0.3046 \\
technical activities & $(0.0011)$ & $(0.0323)$ & $(0.0023)$ & $(0.1023)$ \\
Administrative and support & 0.2287 & 0.2831 & 0.2039 & 0.1038 \\
service activities & $(0.0004)$ & $(0.0441)$ & $(0.0105)$ & $(0.5579)$ \\
Public administration and defense; & 0.6492 & 0.8355 & 0.6785 & 0.7786 \\
compulsory social security & $(0.0000)$ & $(0.0000)$ & $(0.0000)$ & $(0.0000)$ \\
Education & 0.0819 & 0.0349 & 0.1091 & -0.0433 \\
& $(0.1910)$ & $(0.7974)$ & $(0.1504)$ & $(0.8036)$ \\
Human health and social & -0.0599 & -0.1806 & -0.0255 & -0.2221 \\
work activities & $(0.3252)$ & $(0.1848)$ & $(0.7325)$ & $(0.2062)$ \\
\hline Arts, entertainment and recreation & 0.5430 & 0.8739 & 0.6211 & 0.9361 \\
& $(0.0000)$ & $(0.0000)$ & $(0.0000)$ & $(0.0000)$ \\
Other service activities & 0.3728 & 0.7512 & 0.4495 & 0.8028 \\
& $(0.0000)$ & $(0.0000)$ & $(0.0000)$ & $(0.0000)$ \\
\hline 2012 & 0.0119 & 0.0321 & 0.0214 & 0.0642 \\
& $(0.5436)$ & $(0.4066)$ & $(0.3611)$ & $(0.1633)$ \\
2013 & 0.0717 & 0.1211 & 0.0862 & 0.1318 \\
& $(0.0003)$ & $(0.0017)$ & $(0.0003)$ & $(0.0028)$ \\
\hline$\alpha$ & & 2.6217 & & 2.8128 \\
std. dev $(\alpha)$ & & 0.0927 & & 0.1177 \\
\hline$R^{2}$ & 0.138 & & 0.1387 & \\
ln L & & $-53,010.2$ & & $-38,061.7$ \\
Observations & 15,166 & 15,166 & 10,907 & 10,907 \\
\hline & & & & \\
& & &
\end{tabular}

Source: German Job Vacancy Survey 2011-2013. OLS with regional fixed effects. ZTNB means zero-truncated negative binomial regression. Reference group: Plant size $<20$, required qualification: intermediate Agriculture, sector: forestry and fishing, year: 2011. Columns 3 and 4 exclude cases were the decision for the new employee was later than the planed first working day. P-values in brackets. 
Table B.3: Regression on number of applicants II

\begin{tabular}{|c|c|c|c|}
\hline & Unqualified & $\begin{array}{l}\text { Intermediate } \\
\text { qualification }\end{array}$ & $\begin{array}{c}\text { Higher } \\
\text { qualification }\end{array}$ \\
\hline Bargaining & $\begin{array}{c}0.0086 \\
(0.8914) \\
\end{array}$ & $\begin{array}{c}0.0217 \\
(0.3157)\end{array}$ & $\begin{array}{r}-0.0037 \\
(0.9329) \\
\end{array}$ \\
\hline Plant size: $20-49$ & $\begin{array}{c}0.1067 \\
(0.0751)\end{array}$ & $\begin{array}{c}0.0301 \\
(0.2208)\end{array}$ & $\begin{array}{c}0.1362 \\
(0.0184)\end{array}$ \\
\hline $50-199$ & $\begin{array}{c}0.3090 \\
(0.0000)\end{array}$ & $\begin{array}{c}0.2186 \\
(0.0000)\end{array}$ & $\begin{array}{c}0.3038 \\
(0.0000)\end{array}$ \\
\hline $200-499$ & $\begin{array}{c}0.5869 \\
(0.0000)\end{array}$ & $\begin{array}{c}0.4892 \\
(0.0000)\end{array}$ & $\begin{array}{c}0.5765 \\
(0.0000)\end{array}$ \\
\hline $500+$ & $\begin{array}{c}1.0085 \\
(0.0000)\end{array}$ & $\begin{array}{c}0.7034 \\
(0.0000)\end{array}$ & $\begin{array}{c}0.6303 \\
(0.0000)\end{array}$ \\
\hline Low sales & $\begin{array}{c}-0.0981 \\
(0.1628)\end{array}$ & $\begin{array}{c}-0.0904 \\
(0.0017)\end{array}$ & $\begin{array}{r}-0.0540 \\
(0.3322)\end{array}$ \\
\hline Skilled labor shortage & $\begin{array}{r}-0.0016 \\
(0.9798) \\
\end{array}$ & $\begin{array}{r}-0.0712 \\
(0.0081) \\
\end{array}$ & $\begin{array}{r}-0.0932 \\
(0.1220) \\
\end{array}$ \\
\hline Share of highly qualified employees & $\begin{array}{c}0.5045 \\
(0.0403)\end{array}$ & $\begin{array}{c}0.8522 \\
(0.0000)\end{array}$ & $\begin{array}{c}0.1487 \\
(0.0746)\end{array}$ \\
\hline Share of female employees & $\begin{array}{c}0.4247 \\
(0.0005)\end{array}$ & $\begin{array}{c}0.0990 \\
(0.0630)\end{array}$ & $\begin{array}{c}0.3898 \\
(0.0007)\end{array}$ \\
\hline Share of part-time employees & $\begin{array}{r}-0.2719 \\
(0.0242)\end{array}$ & $\begin{array}{r}-0.1967 \\
(0.0002)\end{array}$ & $\begin{array}{r}-0.1086 \\
(0.3468)\end{array}$ \\
\hline Share of temporary employees & $\begin{array}{c}0.0951 \\
(0.4915)\end{array}$ & $\begin{array}{c}0.2327 \\
(0.0012) \\
\end{array}$ & $\begin{array}{c}0.1741 \\
(0.1455) \\
\end{array}$ \\
\hline Newly created job & $\begin{array}{c}0.1982 \\
(0.0009)\end{array}$ & $\begin{array}{c}0.2046 \\
(0.0000)\end{array}$ & $\begin{array}{c}0.1989 \\
(0.0010)\end{array}$ \\
\hline Long-term experience & $\begin{array}{c}-0.0138 \\
(0.7998)\end{array}$ & $\begin{array}{c}0.0972 \\
(0.0000)\end{array}$ & $\begin{array}{c}0.1591 \\
(0.0001)\end{array}$ \\
\hline Leadership abilities & $\begin{array}{c}0.0523 \\
(0.8538)\end{array}$ & $\begin{array}{r}-0.0656 \\
(0.0592)\end{array}$ & $\begin{array}{r}-0.0131 \\
(0.7822)\end{array}$ \\
\hline Part-time job & $\begin{array}{c}-0.0535 \\
(0.4570)\end{array}$ & $\begin{array}{c}0.0670 \\
(0.0461)\end{array}$ & $\begin{array}{c}-0.3818 \\
(0.0000)\end{array}$ \\
\hline Regional unemployment rate & $\begin{array}{c}0.2428 \\
(0.7447) \\
\end{array}$ & $\begin{array}{r}-0.8564 \\
(0.0030) \\
\end{array}$ & $\begin{array}{r}-0.2252 \\
(0.7083) \\
\end{array}$ \\
\hline Mining and quarrying & $\begin{array}{c}0.3147 \\
(0.0808)\end{array}$ & $\begin{array}{c}0.1990 \\
(0.0440)\end{array}$ & $\begin{array}{c}0.4111 \\
(0.3153)\end{array}$ \\
\hline Food; textile, clothes and furniture & $\begin{array}{c}-0.1095 \\
(0.4451)\end{array}$ & $\begin{array}{c}0.2267 \\
(0.0037)\end{array}$ & $\begin{array}{c}0.0518 \\
(0.8493)\end{array}$ \\
\hline Wood, paper and printing & $\begin{array}{c}0.1022 \\
(0.4828)\end{array}$ & $\begin{array}{c}0.4443 \\
(0.0000)\end{array}$ & $\begin{array}{c}0.2371 \\
(0.3862)\end{array}$ \\
\hline $\begin{array}{l}\text { Coke, refined petroleum, } \\
\text { chemicals and plastic products }\end{array}$ & $\begin{array}{c}0.2122 \\
(0.1499)\end{array}$ & $\begin{array}{c}0.4061 \\
(0.0000)\end{array}$ & $\begin{array}{c}0.3125 \\
(0.1906)\end{array}$ \\
\hline $\begin{array}{l}\text { Basic metals, fabricated } \\
\text { metal products }\end{array}$ & $\begin{array}{r}-0.0379 \\
(0.8064)\end{array}$ & $\begin{array}{c}0.3599 \\
(0.0000)\end{array}$ & $\begin{array}{c}0.1257 \\
(0.6269)\end{array}$ \\
\hline $\begin{array}{l}\text { Machinery and equipment, electrical } \\
\text { equipment and motor vehicles }\end{array}$ & $\begin{array}{c}0.1755 \\
(0.4078)\end{array}$ & $\begin{array}{c}0.2819 \\
(0.0003)\end{array}$ & $\begin{array}{c}0.1469 \\
(0.5266)\end{array}$ \\
\hline $\begin{array}{l}\text { Electricity, gas, steam and } \\
\text { air conditioning supply }\end{array}$ & $\begin{array}{c}0.5335 \\
(0.1558)\end{array}$ & $\begin{array}{c}0.9348 \\
(0.0000)\end{array}$ & $\begin{array}{c}0.4881 \\
(0.0381)\end{array}$ \\
\hline $\begin{array}{l}\text { Water supply; sewerage, waste } \\
\text { management and remediation }\end{array}$ & $\begin{array}{c}0.3043 \\
(0.0529)\end{array}$ & $\begin{array}{c}0.6225 \\
(0.0000)\end{array}$ & $\begin{array}{c}0.3782 \\
(0.1380)\end{array}$ \\
\hline activities Construction & $\begin{array}{r}-0.1060 \\
(0.5274) \\
\end{array}$ & $\begin{array}{r}-0.0791 \\
(0.3059) \\
\end{array}$ & $\begin{array}{r}-0.1385 \\
(0.5972) \\
\end{array}$ \\
\hline
\end{tabular}


Table B.3: Regression on number of applicants II

\begin{tabular}{lccc}
\hline & & Intermediate & Higher \\
& Unqualified & qualification & qualification \\
\hline Wholesale and retail trade; repair of & 0.2280 & 0.4604 & 0.1226 \\
motor vehicles and motorcycles & $(0.1918)$ & $(0.0000)$ & $(0.6495)$ \\
\hline Transportation and storage & 0.2502 & 0.3437 & 0.5522 \\
& $(0.0562)$ & $(0.0000)$ & $(0.0525)$ \\
Accommodation and food service & 0.1616 & 0.2334 & 0.3083 \\
activities & $(0.2298)$ & $(0.0013)$ & $(0.3381)$ \\
Information and communication & 0.1377 & 0.4561 & 0.1722 \\
& $(0.5546)$ & $(0.0000)$ & $(0.4558)$ \\
Financial and insurance activities & 0.1037 & 0.2730 & 0.2597 \\
& $(0.7198)$ & $(0.0010)$ & $(0.2827)$ \\
Real estate activities & 0.0940 & 0.8953 & 0.6930 \\
& $(0.6960)$ & $(0.0000)$ & $(0.0041)$ \\
\hline Professional, scientific and & 0.2441 & 0.3996 & -0.0092 \\
technical activities & $(0.3446)$ & $(0.0000)$ & $(0.9681)$ \\
Administrative and support & 0.2011 & 0.3124 & -0.0804 \\
service activities & $(0.1150)$ & $(0.0001)$ & $(0.7793)$ \\
Public administration and defense; & 0.4067 & 0.7937 & 0.5061 \\
compulsory social security & $(0.0109)$ & $(0.0000)$ & $(0.0253)$ \\
Education & 0.3596 & 0.2814 & -0.1850 \\
& $(0.0973)$ & $(0.0002)$ & $(0.4131)$ \\
Human health and social & -0.2209 & 0.0877 & -0.2283 \\
work activities & $(0.0905)$ & $(0.2246)$ & $(0.3240)$ \\
\hline Arts, entertainment and recreation & 0.0889 & 0.5727 & 0.6634 \\
& $(0.5705)$ & $(0.0000)$ & $(0.0068)$ \\
Other service activities & 0.0757 & 0.3804 & 0.5087 \\
& $(0.5862)$ & $(0.0000)$ & $(0.0269)$ \\
\hline 2012 & -0.0765 & 0.0089 & -0.0394 \\
& $(0.1993)$ & $(0.7055)$ & $(0.3946)$ \\
2013 & 0.0949 & 0.0681 & 0.0523 \\
& $(0.1109)$ & $(0.0043)$ & $(0.2536)$ \\
\hline$R^{2}$ & 0.1298 & 0.1300 & 0.1381 \\
Observations & 1,484 & 10,767 & 3,181 \\
\hline
\end{tabular}

Source: German Job Vacancy Survey 2011-2013. Reference group: Plant size $<20$, required qualification: intermediate Agriculture, sector: forestry and fishing, year: 2011. P-values in brackets. 
Table B.4: Regression on number of suitable applicants I

\begin{tabular}{|c|c|c|c|c|}
\hline & $\begin{array}{c}1 \\
\text { OLS }\end{array}$ & $\begin{array}{c}2 \\
\mathrm{ZTNB}\end{array}$ & $\begin{array}{l}3 \\
\text { OLS }\end{array}$ & $\begin{array}{c}4 \\
\mathrm{ZTNB}\end{array}$ \\
\hline Bargaining & $\begin{array}{c}-0.0508 \\
(0.0000)\end{array}$ & $\begin{array}{r}-0.0958 \\
(0.0000)\end{array}$ & $\begin{array}{r}-0.0577 \\
(0.0000)\end{array}$ & $\begin{array}{r}-0.1203 \\
(0.0000)\end{array}$ \\
\hline $\ln$ (Number of applicants) & $\begin{array}{c}0.6315 \\
(0.0000)\end{array}$ & $\begin{array}{c}0.9588 \\
(0.0000)\end{array}$ & $\begin{array}{c}0.6408 \\
(0.0000)\end{array}$ & $\begin{array}{c}0.9575 \\
(0.0000)\end{array}$ \\
\hline Plant size: $20-49$ & $\begin{array}{c}0.0667 \\
(0.0000)\end{array}$ & $\begin{array}{c}0.1004 \\
(0.0000)\end{array}$ & $\begin{array}{c}0.0760 \\
(0.0000)\end{array}$ & $\begin{array}{c}0.1157 \\
(0.0000)\end{array}$ \\
\hline $50-199$ & $\begin{array}{c}0.1072 \\
(0.0000)\end{array}$ & $\begin{array}{c}0.1733 \\
(0.0000)\end{array}$ & $\begin{array}{c}0.1208 \\
(0.0000)\end{array}$ & $\begin{array}{c}0.1826 \\
(0.0000)\end{array}$ \\
\hline $200-499$ & $\begin{array}{c}0.1395 \\
(0.0000)\end{array}$ & $\begin{array}{c}0.2127 \\
(0.0000)\end{array}$ & $\begin{array}{c}0.1338 \\
(0.0000)\end{array}$ & $\begin{array}{c}0.2062 \\
(0.0000)\end{array}$ \\
\hline $500+$ & $\begin{array}{c}0.1719 \\
(0.0000)\end{array}$ & $\begin{array}{c}0.2376 \\
(0.0000)\end{array}$ & $\begin{array}{c}0.1928 \\
(0.0000)\end{array}$ & $\begin{array}{c}0.2641 \\
(0.0000)\end{array}$ \\
\hline Low sales & $\begin{array}{c}0.0035 \\
(0.7997)\end{array}$ & $\begin{array}{c}0.0007 \\
(0.9795)\end{array}$ & $\begin{array}{c}0.0019 \\
(0.9121)\end{array}$ & $\begin{array}{r}-0.0019 \\
(0.9542)\end{array}$ \\
\hline Skilled labor shortage & $\begin{array}{r}-0.1098 \\
(0.0000)\end{array}$ & $\begin{array}{c}-0.1623 \\
(0.0000)\end{array}$ & $\begin{array}{r}-0.1161 \\
(0.0000)\end{array}$ & $\begin{array}{r}-0.1902 \\
(0.0000)\end{array}$ \\
\hline Share of highly qualified employees & $\begin{array}{r}-0.0103 \\
(0.7097)\end{array}$ & $\begin{array}{c}-0.1001 \\
(0.0317)\end{array}$ & $\begin{array}{r}-0.0092 \\
(0.7746)\end{array}$ & $\begin{array}{r}-0.1119 \\
(0.0392)\end{array}$ \\
\hline Share of female employees & $\begin{array}{r}-0.0267 \\
(0.2855)\end{array}$ & $\begin{array}{r}-0.0071 \\
(0.8771)\end{array}$ & $\begin{array}{r}-0.0330 \\
(0.2608)\end{array}$ & $\begin{array}{r}-0.0097 \\
(0.8549)\end{array}$ \\
\hline Share of part-time employees & $\begin{array}{c}0.0627 \\
(0.0127)\end{array}$ & $\begin{array}{c}0.1036 \\
(0.0232)\end{array}$ & $\begin{array}{c}0.0782 \\
(0.0076)\end{array}$ & $\begin{array}{c}0.1390 \\
(0.0074)\end{array}$ \\
\hline Share of temporary employees & $\begin{array}{c}0.0759 \\
(0.0115)\end{array}$ & $\begin{array}{c}0.1433 \\
(0.0067)\end{array}$ & $\begin{array}{c}0.0702 \\
(0.0402) \\
\end{array}$ & $\begin{array}{c}0.1092 \\
(0.0647) \\
\end{array}$ \\
\hline Newly created job & $\begin{array}{r}-0.0025 \\
(0.8499)\end{array}$ & $\begin{array}{c}-0.0235 \\
(0.3128)\end{array}$ & $\begin{array}{c}-0.0003 \\
(0.9861)\end{array}$ & $\begin{array}{r}-0.0259 \\
(0.3252)\end{array}$ \\
\hline Required qualifikation: Unqualified & $\begin{array}{c}0.0024 \\
(0.8816)\end{array}$ & $\begin{array}{c}0.0291 \\
(0.3423)\end{array}$ & $\begin{array}{r}-0.0096 \\
(0.6079)\end{array}$ & $\begin{array}{r}-0.0033 \\
(0.9275)\end{array}$ \\
\hline Required qualifikation: High & $\begin{array}{r}-0.0200 \\
(0.1669)\end{array}$ & $\begin{array}{c}0.0187 \\
(0.4349)\end{array}$ & $\begin{array}{r}-0.0228 \\
(0.1792)\end{array}$ & $\begin{array}{c}0.0253 \\
(0.3688)\end{array}$ \\
\hline Long-term experience & $\begin{array}{r}-0.0598 \\
(0.0000)\end{array}$ & $\begin{array}{r}-0.1039 \\
(0.0000)\end{array}$ & $\begin{array}{r}-0.0594 \\
(0.0000)\end{array}$ & $\begin{array}{r}-0.0944 \\
(0.0000)\end{array}$ \\
\hline Managerial skills & $\begin{array}{r}-0.0083 \\
(0.6055)\end{array}$ & $\begin{array}{r}-0.0127 \\
(0.6670)\end{array}$ & $\begin{array}{r}-0.0233 \\
(0.2052)\end{array}$ & $\begin{array}{r}-0.0466 \\
(0.1673)\end{array}$ \\
\hline Part-time job & $\begin{array}{c}0.0052 \\
(0.7241)\end{array}$ & $\begin{array}{c}-0.0133 \\
(0.6076)\end{array}$ & $\begin{array}{c}0.0065 \\
(0.7039)\end{array}$ & $\begin{array}{r}-0.0109 \\
(0.7075)\end{array}$ \\
\hline Regional unemployment rate & $\begin{array}{c}-0.0059 \\
(0.9656) \\
\end{array}$ & $\begin{array}{c}-0.1873 \\
(0.4557)\end{array}$ & $\begin{array}{c}0.0498 \\
(0.7570) \\
\end{array}$ & $\begin{array}{r}-0.0895 \\
(0.7566) \\
\end{array}$ \\
\hline Mining and quarrying & $\begin{array}{c}0.0285 \\
(0.5663)\end{array}$ & $\begin{array}{c}0.0378 \\
(0.7403)\end{array}$ & $\begin{array}{c}0.0079 \\
(0.8936)\end{array}$ & $\begin{array}{r}-0.0030 \\
(0.9825)\end{array}$ \\
\hline Food; textile, clothes and furniture & $\begin{array}{c}-0.0474 \\
(0.2178)\end{array}$ & $\begin{array}{r}-0.1437 \\
(0.1311)\end{array}$ & $\begin{array}{r}-0.0618 \\
(0.1803)\end{array}$ & $\begin{array}{r}-0.1801 \\
(0.1097)\end{array}$ \\
\hline Wood, paper and printing & $\begin{array}{r}-0.0102 \\
(0.8029)\end{array}$ & $\begin{array}{r}-0.0421 \\
(0.6629)\end{array}$ & $\begin{array}{r}-0.0399 \\
(0.4197)\end{array}$ & $\begin{array}{r}-0.1011 \\
(0.3689)\end{array}$ \\
\hline $\begin{array}{l}\text { Coke, refined petroleum, } \\
\text { chemicals and plastic products }\end{array}$ & $\begin{array}{c}0.0008 \\
(0.9838)\end{array}$ & $\begin{array}{r}-0.0295 \\
(0.7483)\end{array}$ & $\begin{array}{r}-0.0284 \\
(0.5508)\end{array}$ & $\begin{array}{r}-0.0886 \\
(0.4201)\end{array}$ \\
\hline $\begin{array}{l}\text { Basic metals, fabricated } \\
\text { metal products }\end{array}$ & $\begin{array}{r}-0.0553 \\
(0.1566)\end{array}$ & $\begin{array}{r}-0.0921 \\
(0.3411)\end{array}$ & $\begin{array}{r}-0.0960 \\
(0.0459)\end{array}$ & $\begin{array}{r}-0.1475 \\
(0.2044)\end{array}$ \\
\hline $\begin{array}{l}\text { Machinery and equipment, electrical } \\
\text { equipment and motor vehicles }\end{array}$ & $\begin{array}{r}-0.0260 \\
(0.4920)\end{array}$ & $\begin{array}{r}-0.0587 \\
(0.5224)\end{array}$ & $\begin{array}{r}-0.0567 \\
(0.2127)\end{array}$ & $\begin{array}{r}-0.1141 \\
(0.2948)\end{array}$ \\
\hline & & & & \\
\hline
\end{tabular}


Table B.4: Regression on number of suitable applicants I

\begin{tabular}{|c|c|c|c|c|}
\hline & $\begin{array}{l}1 \\
\text { OLS }\end{array}$ & $\begin{array}{c}2 \\
\mathrm{ZTNB}\end{array}$ & $\begin{array}{l}3 \\
\text { OLS }\end{array}$ & $\begin{array}{c}4 \\
\mathrm{ZTNB}\end{array}$ \\
\hline $\begin{array}{l}\text { Electricity, gas, steam and } \\
\text { air conditioning supply }\end{array}$ & $\begin{array}{c}0.0244 \\
(0.5566)\end{array}$ & $\begin{array}{r}-0.0651 \\
(0.4909)\end{array}$ & $\begin{array}{c}0.0151 \\
(0.7535)\end{array}$ & $\begin{array}{r}-0.1183 \\
(0.2791)\end{array}$ \\
\hline Water supply; sewerage, waste & 0.0513 & 0.0538 & 0.0393 & 0.0076 \\
\hline ent and remediation & $(0.2000)$ & $(0.5636)$ & $(0.4067)$ & $(0.9436)$ \\
\hline activities Construction & $\begin{array}{r}-0.0085 \\
(0.8278)\end{array}$ & $\begin{array}{r}-0.0868 \\
(0.3928)\end{array}$ & $\begin{array}{r}-0.0317 \\
(0.5167)\end{array}$ & $\begin{array}{r}-0.1224 \\
(0.3244)\end{array}$ \\
\hline $\begin{array}{l}\text { Wholesale and retail trade; repair of } \\
\text { motor vehicles and motorcycles }\end{array}$ & $\begin{array}{r}-0.0371 \\
(0.3389)\end{array}$ & $\begin{array}{r}-0.1153 \\
(0.2199)\end{array}$ & $\begin{array}{r}-0.0807 \\
(0.0826)\end{array}$ & $\begin{array}{r}-0.1928 \\
(0.0815)\end{array}$ \\
\hline Transportation and storage & $\begin{array}{c}0.0156 \\
(0.6987)\end{array}$ & $\begin{array}{c}0.0369 \\
(0.6989)\end{array}$ & $\begin{array}{r}-0.0239 \\
(0.6251)\end{array}$ & $\begin{array}{r}-0.0484 \\
(0.6664)\end{array}$ \\
\hline $\begin{array}{l}\text { Accommodation and food service } \\
\text { activities }\end{array}$ & $\begin{array}{r}-0.0239 \\
(0.5256)\end{array}$ & $\begin{array}{r}-0.0571 \\
(0.5335)\end{array}$ & $\begin{array}{r}-0.0625 \\
(0.1690)\end{array}$ & $\begin{array}{r}-0.1285 \\
(0.2389)\end{array}$ \\
\hline Information and communication & $\begin{array}{r}-0.0333 \\
(0.4080)\end{array}$ & $\begin{array}{r}-0.0669 \\
(0.4763)\end{array}$ & $\begin{array}{r}-0.0534 \\
(0.2660)\end{array}$ & $\begin{array}{r}-0.1266 \\
(0.2515)\end{array}$ \\
\hline Financial and insur: & $\begin{array}{c}0.0034 \\
(0.9345)\end{array}$ & $\begin{array}{c}0.0121 \\
(0.8985)\end{array}$ & $\begin{array}{c}0.0099 \\
(0.8351)\end{array}$ & $\begin{array}{c}0.0012 \\
(0.9912)\end{array}$ \\
\hline Real estate activities & $\begin{array}{c}0.0253 \\
(0.5499) \\
\end{array}$ & $\begin{array}{r}-0.0081 \\
(0.9319)\end{array}$ & $\begin{array}{r}-0.0297 \\
(0.5497)\end{array}$ & $\begin{array}{r}-0.1218 \\
(0.2736) \\
\end{array}$ \\
\hline itific and & $\begin{array}{r}-0.0423 \\
(0.2808)\end{array}$ & $\begin{array}{r}-0.1112 \\
(0.2301)\end{array}$ & $\begin{array}{c}-0.0651 \\
(0.1721)\end{array}$ & $\begin{array}{r}-0.1367 \\
(0.2120)\end{array}$ \\
\hline $\begin{array}{l}\text { Administrative and support } \\
\text { service activities }\end{array}$ & $\begin{array}{r}-0.0230 \\
(0.5549)\end{array}$ & $\begin{array}{r}-0.0329 \\
(0.7255)\end{array}$ & $\begin{array}{r}-0.0476 \\
(0.3095)\end{array}$ & $\begin{array}{r}-0.0794 \\
(0.4728)\end{array}$ \\
\hline $\begin{array}{l}\text { Public administration and defense; } \\
\text { compulsory social security }\end{array}$ & $\begin{array}{c}0.2672 \\
(0.0000)\end{array}$ & $\begin{array}{c}0.2950 \\
(0.0006)\end{array}$ & $\begin{array}{c}0.2281 \\
(0.0000)\end{array}$ & $\begin{array}{c}0.2141 \\
(0.0327)\end{array}$ \\
\hline Educ & $\begin{array}{c}0.1304 \\
(0.0004)\end{array}$ & $\begin{array}{c}0.2102 \\
(0.0178)\end{array}$ & $\begin{array}{c}0.1087 \\
(0.0123)\end{array}$ & $\begin{array}{c}0.1527 \\
(0.1371)\end{array}$ \\
\hline $\begin{array}{l}\text { Human health and social } \\
\text { work activities }\end{array}$ & $\begin{array}{c}0.0376 \\
(0.2953)\end{array}$ & $\begin{array}{c}0.0465 \\
(0.5995)\end{array}$ & $\begin{array}{c}0.0234 \\
(0.5843)\end{array}$ & $\begin{array}{c}0.0012 \\
(0.9910)\end{array}$ \\
\hline Arts, entertainment and recreation & $\begin{array}{c}0.0810 \\
(0.0583)\end{array}$ & $\begin{array}{c}0.0966 \\
(0.3147)\end{array}$ & $\begin{array}{c}0.0687 \\
(0.1750)\end{array}$ & $\begin{array}{c}0.0542 \\
(0.6273)\end{array}$ \\
\hline Other & $\begin{array}{c}0.0856 \\
(0.0190) \\
\end{array}$ & $\begin{array}{c}0.0327 \\
(0.7109) \\
\end{array}$ & $\begin{array}{c}0.0486 \\
(0.2669) \\
\end{array}$ & $\begin{array}{r}-0.0464 \\
(0.6526) \\
\end{array}$ \\
\hline 2012 & $\begin{array}{c}0.0002 \\
(0.9886)\end{array}$ & $\begin{array}{c}-0.0143 \\
(0.4828)\end{array}$ & $\begin{array}{r}-0.0068 \\
(0.6021)\end{array}$ & $\begin{array}{r}-0.0361 \\
(0.1253)\end{array}$ \\
\hline 2013 & $\begin{array}{c}0.0048 \\
(0.6694) \\
\end{array}$ & $\begin{array}{r}-0.0050 \\
(0.8015) \\
\end{array}$ & $\begin{array}{r}-0.0074 \\
(0.5784) \\
\end{array}$ & $\begin{array}{r}-0.0241 \\
(0.2972) \\
\end{array}$ \\
\hline $\begin{array}{l}\alpha \\
\text { std. }\end{array}$ & & $\begin{array}{l}0.3598 \\
0.0109\end{array}$ & & $\begin{array}{l}0.3557 \\
0.0122\end{array}$ \\
\hline$R^{2}$ & 0.623 & & 0.6369 & \\
\hline $\begin{array}{l}\ln \mathrm{L} \\
\text { Observations }\end{array}$ & 14,519 & $\begin{array}{c}-25,913.4 \\
14,519\end{array}$ & 10,462 & $\begin{array}{c}-18,998.0 \\
10,462\end{array}$ \\
\hline
\end{tabular}

Source: German Job Vacancy Survey 2011-2013. ZTNB means zero-truncated negative binomial regression. Reference group: Plant size $<20$, required qualification: intermediate Agriculture, sector: forestry and fishing, year: 2011. Columns 3 and 4 exclude cases were the decision for the new employee was later than the planed first working day. P-values in brackets. 
Table B.5: Regression on number of suitable applicants II

\begin{tabular}{|c|c|c|c|}
\hline & Unqualified & $\begin{array}{l}\text { Intermediate } \\
\text { qualification }\end{array}$ & $\begin{array}{c}\text { Higher } \\
\text { qualification }\end{array}$ \\
\hline Bargaining & $\begin{array}{c}0.0166 \\
(0.6691)\end{array}$ & $\begin{array}{r}-0.0560 \\
(0.0000)\end{array}$ & $\begin{array}{r}-0.0523 \\
(0.0373)\end{array}$ \\
\hline $\ln$ (Number of applicants) & $\begin{array}{c}0.6877 \\
(0.0000)\end{array}$ & $\begin{array}{c}0.6268 \\
(0.0000)\end{array}$ & $\begin{array}{c}0.6217 \\
(0.0000)\end{array}$ \\
\hline Plant size: $20-49$ & $\begin{array}{l}(0.0790) \\
(0.0284)\end{array}$ & $\begin{array}{l}(0.0665) \\
(0.0000)\end{array}$ & $\begin{array}{l}(0.0562) \\
(0.0727)\end{array}$ \\
\hline $50-199$ & $\begin{array}{c}0.1501 \\
(0.0002)\end{array}$ & $\begin{array}{c}0.1184 \\
(0.0000)\end{array}$ & $\begin{array}{c}0.0431 \\
(0.1777)\end{array}$ \\
\hline $200-499$ & $\begin{array}{c}0.2149 \\
(0.0002)\end{array}$ & $\begin{array}{c}0.1365 \\
(0.0000)\end{array}$ & $\begin{array}{c}0.1177 \\
(0.0035)\end{array}$ \\
\hline $500+$ & $\begin{array}{c}0.3932 \\
(0.0000)\end{array}$ & $\begin{array}{c}0.2375 \\
(0.0000)\end{array}$ & $\begin{array}{c}0.0468 \\
(0.2725)\end{array}$ \\
\hline Low sales & $\begin{array}{r}-0.0308 \\
(0.4755)\end{array}$ & $\begin{array}{c}0.0166 \\
(0.3099)\end{array}$ & $\begin{array}{r}-0.0084 \\
(0.7985)\end{array}$ \\
\hline Skilled labor shortage & $\begin{array}{r}-0.0529 \\
(0.1596)\end{array}$ & $\begin{array}{c}-0.1116 \\
(0.0000)\end{array}$ & $\begin{array}{r}-0.1416 \\
(0.0001)\end{array}$ \\
\hline share of highly qualified employees & $\begin{array}{c}0.0592 \\
(0.6793)\end{array}$ & $\begin{array}{c}-0.0506 \\
(0.1657)\end{array}$ & $\begin{array}{r}-0.0237 \\
(0.6134)\end{array}$ \\
\hline Share of female employees & $\begin{array}{r}-0.1087 \\
(0.1185)\end{array}$ & $\begin{array}{c}-0.0014 \\
(0.9617)\end{array}$ & $\begin{array}{r}-0.1194 \\
(0.0662)\end{array}$ \\
\hline Share of part-time employees & $\begin{array}{c}-0.0649 \\
(0.3801)\end{array}$ & $\begin{array}{c}0.0849 \\
(0.0040)\end{array}$ & $\begin{array}{c}0.0276 \\
(0.6713)\end{array}$ \\
\hline Share of temporary employees & $\begin{array}{c}0.1495 \\
(0.0487)\end{array}$ & $\begin{array}{c}0.0430 \\
(0.2520) \\
\end{array}$ & $\begin{array}{c}0.0593 \\
(0.3422) \\
\end{array}$ \\
\hline Newly created job & $\begin{array}{r}-0.0190 \\
(0.5904)\end{array}$ & $\begin{array}{r}-0.0072 \\
(0.6399)\end{array}$ & $\begin{array}{c}0.0345 \\
(0.3063)\end{array}$ \\
\hline Long-term experience & $\begin{array}{r}-0.1190 \\
(0.0005)\end{array}$ & $\begin{array}{r}-0.0365 \\
(0.0011)\end{array}$ & $\begin{array}{r}-0.0959 \\
(0.0000)\end{array}$ \\
\hline Managerial skills & $\begin{array}{c}0.0850 \\
(0.6676)\end{array}$ & $\begin{array}{r}-0.0367 \\
(0.0671)\end{array}$ & $\begin{array}{c}0.0187 \\
(0.4904)\end{array}$ \\
\hline Part-time job & $\begin{array}{c}0.0480 \\
(0.2240)\end{array}$ & $\begin{array}{c}0.0165 \\
(0.3561)\end{array}$ & $\begin{array}{r}-0.0386 \\
(0.2885)\end{array}$ \\
\hline Regional unemployment rate & $\begin{array}{c}0.6551 \\
(0.1301) \\
\end{array}$ & $\begin{array}{c}-0.1380 \\
(0.3834) \\
\end{array}$ & $\begin{array}{c}0.3545 \\
(0.3087) \\
\end{array}$ \\
\hline Mining and quarrying & $\begin{array}{c}0.1603 \\
(0.1620)\end{array}$ & $\begin{array}{c}0.0552 \\
(0.3085)\end{array}$ & $\begin{array}{r}-0.4650 \\
(0.0314)\end{array}$ \\
\hline Food; textile, clothes and furniture & $\begin{array}{r}-0.0328 \\
(0.7268)\end{array}$ & $\begin{array}{r}-0.0179 \\
(0.6736)\end{array}$ & $\begin{array}{r}-0.3241 \\
(0.0365)\end{array}$ \\
\hline Wood, paper and printing & $\begin{array}{c}0.0001 \\
(0.9996)\end{array}$ & $\begin{array}{c}0.0401 \\
(0.3779)\end{array}$ & $\begin{array}{r}-0.4053 \\
(0.0069)\end{array}$ \\
\hline $\begin{array}{l}\text { Coke, refined petroleum, } \\
\text { chemicals and plastic products }\end{array}$ & $\begin{array}{c}0.0017 \\
(0.9866)\end{array}$ & $\begin{array}{c}0.0470 \\
(0.2812)\end{array}$ & $\begin{array}{r}-0.2913 \\
(0.0391)\end{array}$ \\
\hline $\begin{array}{l}\text { Basic metals, fabricated } \\
\text { metal products }\end{array}$ & $\begin{array}{r}-0.0265 \\
(0.7874)\end{array}$ & $\begin{array}{r}-0.0233 \\
(0.5873)\end{array}$ & $\begin{array}{r}-0.3114 \\
(0.0356)\end{array}$ \\
\hline $\begin{array}{l}\text { Machinery and equipment, electrical } \\
\text { equipment and motor vehicles }\end{array}$ & $\begin{array}{r}-0.0045 \\
(0.9706)\end{array}$ & $\begin{array}{c}0.0363 \\
(0.3792)\end{array}$ & $\begin{array}{r}-0.3301 \\
(0.0161)\end{array}$ \\
\hline $\begin{array}{l}\text { Electricity, gas, steam and } \\
\text { air conditioning supply }\end{array}$ & $\begin{array}{r}-0.0287 \\
(0.9034)\end{array}$ & $\begin{array}{c}0.1258 \\
(0.0075)\end{array}$ & $\begin{array}{r}-0.3466 \\
(0.0117)\end{array}$ \\
\hline $\begin{array}{l}\text { Water supply; sewerage, waste } \\
\text { management and remediation }\end{array}$ & $\begin{array}{r}-0.0803 \\
(0.4069)\end{array}$ & $\begin{array}{c}0.0929 \\
(0.0388)\end{array}$ & $\begin{array}{r}-0.1075 \\
(0.4565)\end{array}$ \\
\hline $\mathrm{d}$ ne & & & \\
\hline
\end{tabular}


Table B.5: Regression on number of suitable applicants II

\begin{tabular}{|c|c|c|c|}
\hline & Unqualified & $\begin{array}{l}\text { Intermediate } \\
\text { qualification }\end{array}$ & $\begin{array}{c}\text { Higher } \\
\text { qualification }\end{array}$ \\
\hline activities Construction & $\begin{array}{r}-0.0768 \\
(0.4730)\end{array}$ & $\begin{array}{c}0.0371 \\
(0.3868)\end{array}$ & $\begin{array}{r}-0.2733 \\
(0.0836)\end{array}$ \\
\hline $\begin{array}{l}\text { Wholesale and retail trade; repair of } \\
\text { motor vehicles and motorcycles }\end{array}$ & $\begin{array}{r}-0.0543 \\
(0.6246)\end{array}$ & $\begin{array}{r}-0.0089 \\
(0.8329)\end{array}$ & $\begin{array}{r}-0.2208 \\
(0.1449)\end{array}$ \\
\hline Transportation and storage & $\begin{array}{r}-0.0541 \\
(0.5409)\end{array}$ & $\begin{array}{c}0.0672 \\
(0.1394)\end{array}$ & $\begin{array}{r}-0.3368 \\
(0.0535)\end{array}$ \\
\hline $\begin{array}{l}\text { Accommodation and food service } \\
\text { activities }\end{array}$ & $\begin{array}{r}-0.1312 \\
(0.1521)\end{array}$ & $\begin{array}{c}0.0347 \\
(0.4017)\end{array}$ & $\begin{array}{r}-0.2401 \\
(0.2040)\end{array}$ \\
\hline Information and communication & $\begin{array}{c}0.1824 \\
(0.1885)\end{array}$ & $\begin{array}{c}0.0038 \\
(0.9357)\end{array}$ & $\begin{array}{r}-0.2987 \\
(0.0278)\end{array}$ \\
\hline Financial and insurance activities & $\begin{array}{c}0.1400 \\
(0.2499)\end{array}$ & $\begin{array}{c}0.0450 \\
(0.3117)\end{array}$ & $\begin{array}{r}-0.2838 \\
(0.0481)\end{array}$ \\
\hline Real estate activities & $\begin{array}{c}0.0522 \\
(0.7273)\end{array}$ & $\begin{array}{c}0.0467 \\
(0.3114)\end{array}$ & $\begin{array}{r}-0.1539 \\
(0.2953)\end{array}$ \\
\hline $\begin{array}{l}\text { Professional, scientific and } \\
\text { technical activities }\end{array}$ & $\begin{array}{r}-0.2663 \\
(0.1133)\end{array}$ & $\begin{array}{c}0.0151 \\
(0.7464)\end{array}$ & $\begin{array}{r}-0.2977 \\
(0.0258)\end{array}$ \\
\hline $\begin{array}{l}\text { Administrative and support } \\
\text { service activities }\end{array}$ & $\begin{array}{r}-0.0414 \\
(0.6297)\end{array}$ & $\begin{array}{r}-0.0298 \\
(0.4943)\end{array}$ & $\begin{array}{c}0.0483 \\
(0.7780)\end{array}$ \\
\hline $\begin{array}{l}\text { Public administration and defense; } \\
\text { compulsory social security }\end{array}$ & $\begin{array}{c}0.2288 \\
(0.0196)\end{array}$ & $\begin{array}{c}0.3192 \\
(0.0000)\end{array}$ & $\begin{array}{c}0.0014 \\
(0.9917)\end{array}$ \\
\hline Education & $\begin{array}{r}-0.0008 \\
(0.9949)\end{array}$ & $\begin{array}{c}0.1713 \\
(0.0000)\end{array}$ & $\begin{array}{r}-0.0971 \\
(0.4612)\end{array}$ \\
\hline $\begin{array}{l}\text { Human health and social } \\
\text { work activities }\end{array}$ & $\begin{array}{r}-0.0450 \\
(0.6033)\end{array}$ & $\begin{array}{c}0.0618 \\
(0.1228)\end{array}$ & $\begin{array}{r}-0.1050 \\
(0.4345) \\
\end{array}$ \\
\hline Arts, entertainment and recreation & $\begin{array}{r}-0.0439 \\
(0.6572)\end{array}$ & $\begin{array}{c}0.0844 \\
(0.0875)\end{array}$ & $\begin{array}{c}0.0031 \\
(0.9826)\end{array}$ \\
\hline Other service activities & $\begin{array}{c}0.0819 \\
(0.3692)\end{array}$ & $\begin{array}{c}0.1014 \\
(0.0138)\end{array}$ & $\begin{array}{r}-0.1017 \\
(0.4451)\end{array}$ \\
\hline 2012 & $\begin{array}{r}-0.0177 \\
(0.6219)\end{array}$ & $\begin{array}{c}0.0034 \\
(0.7923)\end{array}$ & $\begin{array}{r}-0.0005 \\
(0.9862)\end{array}$ \\
\hline 2013 & $\begin{array}{r}-0.0009 \\
(0.9789)\end{array}$ & $\begin{array}{c}0.0124 \\
(0.3462)\end{array}$ & $\begin{array}{r}-0.0041 \\
(0.8770)\end{array}$ \\
\hline$R^{2}$ & 0.6471 & 0.6308 & 0.5894 \\
\hline Observations & 1,371 & 10,118 & 3,030 \\
\hline
\end{tabular}

Source: German Job Vacancy Survey 2011-2013. Reference group: Plant size $<20$, required qualification: intermediate Agriculture, sector: forestry and fishing, year: 2011. P-values in brackets. 
Table B.6: Robustness check, number of (suitable) applicants

\begin{tabular}{lcccc}
\hline & \multicolumn{2}{c}{ Number of applicants } & \multicolumn{2}{c}{ Number of suitable applicants } \\
& OLS & ZTNB & OLS & ZTNB \\
\hline Bargaining & 0.0200 & 0.0320 & -0.0433 & -0.0836 \\
& $(0.2851)$ & $(0.4102)$ & $(0.0000)$ & $(0.0000)$ \\
Collective Contract & 0.0454 & 0.0773 & 0.0510 & 0.0862 \\
& $(0.0139)$ & $(0.0356)$ & $(0.0000)$ & $(0.0000)$ \\
\hline Pseudo $R^{2}$ & 0.1370 & & 0.6233 & $-25,253.5$ \\
ln L & & $-51,708.6$ & & 14,162 \\
Observations & 14,788 & 14,788 & 14,162 & \\
\hline
\end{tabular}

Source: German Job Vacancy Survey 2011-2013. Same control variables as in the other regressions. P-values in brackets. 